Article

\title{
Synthesis of Mono- and Bis-Pyrazoles Bearing Flexible $p$-Tolyl Ether and Rigid Xanthene Backbones, and Their Potential as Ligands in the Pd-Catalysed Suzuki-Miyaura Cross-Coupling Reaction
}

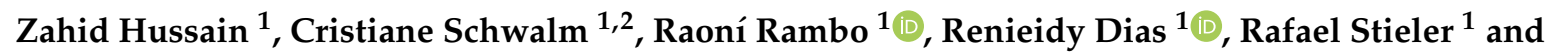 \\ Adriano Monteiro ${ }^{1, *(1)}$ \\ 1 Laboratory of Molecular Catalysis, Institute of Chemistry, Federal University of Rio Grande do Sul, \\ Av. Bento Gonçalves, 9500, Porto Alegre 91501-970, RS, Brazil \\ 2 Faculty of Exact Science and Technology, Federal University of Grande Dourados, Rodovia \\ Dourados-Itahum, km 12, Dourados 79804-970, MS, Brazil \\ * Correspondence: adriano.monteiro@ufrgs.br; Tel.: +55-051-3308-9628
}

Received: 29 July 2019; Accepted: 21 August 2019; Published: 26 August 2019

check for updates

\begin{abstract}
The present work describes the synthesis of mono- and bis-pyrazole compounds bearing flexible $p$-tolyl ether and rigid 4,5-dibromo-2,7-di-tert-butyl-9,9-dimethyl-9H-xanthene backbones as pyrazolyl analogues of DPEphos and Xantphos ligands, respectively. The synthesis of new pyrazolyl analogues was accomplished following an Ullmann coupling protocol, and the resulting products were isolated in overall good yields. In addition, a hybrid imidazolyl-pyrazolyl analogue bearing a xanthene backbone was synthesized using the same protocol, whereas a hybrid selanyl-pyrazolyl analogue with a xanthene backbone was synthesized in a good yield employing a second $\mathrm{C}-\mathrm{H}$ activation step. The symmetrical bis-pyrazolyl and the hybrid imidazolyl-pyrazolyl analogues were found to be the most active among the new ligands evaluated in the Pd-catalysed Suzuki-Miyaura cross-coupling of aryl halides with aryl boronic acids. A simple catalytic system based on $\mathrm{Pd}(\mathrm{OAc})_{2} / 2 \mathbf{a}$ was developed, which efficiently catalyses the Suzuki-Miyaura reaction of aryl halides and aryl boronic acids and provides moderate to excellent yields of the corresponding cross-coupling products.
\end{abstract}

Keywords: pyrazolyl ligands; Suzuki-Miyaura cross-coupling; palladium; homogenous catalysis; aryl halides; aryl boronic acids; Ullmann coupling; $\mathrm{C}-\mathrm{H}$ activation

\section{Introduction}

Transition metal complexes of phosphorous $(P)$, nitrogen $(N)$, sulphur $(S)$, and oxygen $(O)$-based ligands and their hybrids have provided chemists with a wide opportunity and a quasi-exhaustive tool for creating $\mathrm{C}-\mathrm{C}$ bonds of significant interest $[1,2]$. The reactivity and the catalytic behaviour of these complexes largely depend on the nature of the coordinating atoms, their relative position within the molecular architecture, and the relative flexibility or rigidity of the ligand backbone, as they greatly influence steric and electronic properties of the resulting complex [3,4]. Therefore, the fine-tuning of these properties in order to synthesize ligands of particular interest has been an interesting strategy. In this perspective, a plethora of ligands with flexible backbones, such as DPEphos, rigid backbones containing bulky substituents, such as ${ }^{t} \mathrm{Bu}$-Xantphos, and other xanthene scaffolds have been widely described in the literature [5-7]. In addition to the diphosphines bearing a xanthene backbone, the corresponding analogues displaying diamido [8], diamine [9], disilyl [10], and dithiolates [11] as coordination units have also been described. Moreover, since these xanthene-derived ligands possess wide bite angles, they can coordinate with a variety of metals, and the corresponding metal 
complexes have been successfully applied to a wide variety of reactions, such as hydroformylation, alkoxy-carbonylation, hydrocyanation, cross-coupling reactions (for $\mathrm{C}-\mathrm{C}$ and $\mathrm{C}-\mathrm{X}$ bond formation), and carbonylative coupling reactions [12].

Although the synthesis of modified ligands and catalytic systems based on phosphines is still an active part of ongoing research, the efforts for the development of phosphine-free catalysts for cross-coupling reactions and other related transformations have experienced rapid growth during the last $2-4$ decades $[13,14]$. Among the cross-coupling reactions, the Suzuki-Miyaura (SM) reaction has been widely explored as a powerful tool for $C-C$ bond formation due to several reasons [15-19]. Therefore, great effort has been made to search for greener reaction conditions, including the development of new catalytic systems and the design of new nitrogen-based ligands, by both academia and industry worldwide [20,21]. Thus far, the majority of the $\mathrm{N}$-based ligands for the Pd-catalysed C-C bond formation are based on alkyl or aryl amines [22,23], pyridines [24], imines [25], imidazoles in the form of $\mathrm{N}$-heterocyclic carbenes (NHC's) [26], oxazolines [27], and their hybrids [28,29], whereas the corresponding pyrazole-based ligands have been relatively less explored [28,30]. Among the few examples reported in the literature, hybrid unsymmetrical benzimidazolium-pyrazolyl $\mathrm{N}, \mathrm{N}$-ligands, pyridine-pyrazolyl $\mathrm{N}, \mathrm{N}$-ligands, and bulky monodentate pyrazolyl ligands have been successfully applied for the Pd-catalysed Suzuki cross-coupling reactions [31-33]. Nevertheless, pyrazole-based catalysts have been employed in other important $\mathrm{C}-\mathrm{C}$ bond forming reactions such as oligomerisations [34], polymerisations, and copolymerisations [35].

Previously, we reported some palladium complexes of bis-pyrazolyl tridentate ligands and demonstrated their application in the Suzuki-Miyaura cross-coupling reaction [36]. To the best of our knowledge, pyrazolyl ligands based on a flexible $p$-tolyl ether or rigid xanthene backbones have not been described in the literature, inspiring us to synthesize some pyrazolyl analogues of DPEphos and Xantphos (Figure 1), and evaluate their potential as ligands in the Pd-catalysed SM cross-coupling of aryl halides with aryl boronic acids.

Phosphine Ligands<smiles>Pc1ccccc1Oc1ccccc1Pc1ccccc1</smiles>

DPEphos<smiles>[Y]C1(C)c2cccc(-c3ccccc3)c2Oc2c(-c3ccccc3)cccc21</smiles>

Xantphos

Pyrazolyl Analogues<smiles>Cc1ccc(Oc2ccc(C)cc2-n2cccn2)c(-n2cccn2)c1</smiles><smiles>CC(C)(C)c1cc(-n2cccn2)c2c(c1)C(C)(C)c1cc(C(C)(C)C)cc(-n3cccn3)c1O2</smiles>

Figure 1. Pyrazolyl analogues of bis[(2-diphenylphosphino)phenyl] ether (DPEPhos) and (4,5-bis(diphenylphosphino)-9,9-dimethylxanthene (Xantphos).

\section{Results and Discussion}

A two-step bromination/Ullmann coupling reaction sequence was designed in order to synthesize the new pyrazolyl analogue of DPEphos (Scheme 1). p-tolyl ether was chosen as the starting material to avoid the $o / p$ selectivity issues in the bromination step through blockage of the $p$-position. The dibromination of $p$-tolyl ether was successfully accomplished by the reaction with 
$\mathrm{N}$-bromosuccinimide (NBS) using $20 \mathrm{~mol} \%$ of ammonium acetate as catalyst in acetonitrile at room temperature [37]. After chromatographic separation followed by recrystallization in pentane, the titled dibromo product, 4,4'-oxybis(3-bromo-1-methylbenzene) (1) was obtained in $68 \%$ yield. It is important to mention that this dibromination reaction is a much milder and simpler approach to this product compared to the previous protocol reported in the literature, which employed an ortho-lithiation strategy [38]. Then, 1 was used as the substrate for the Ullmann coupling reaction with $1 H$-pyrazole (Scheme 1). The reaction of 1 with $1 H$-pyrazole (a) using a $\mathrm{Cu}_{2} \mathrm{O} /$ phenanthroline catalytic system in $\mathrm{N}, \mathrm{N}$-dimethylformamide (DMF) at $140^{\circ} \mathrm{C}$ for $48 \mathrm{~h}$ of magnetic stirring provided the symmetrical bis-pyrazolyl analogue 1a in $47 \%$ isolated yield, along with $37 \%$ of the dehalogenated mono-pyrazolyl derivative $\mathbf{1 a}^{\prime}$ as a byproduct (Scheme 1). Attempts to optimise the catalytic system provided no significant improvements in the selectivity for compound 1a. Despite the moderate yield for 1a, this protocol further allows the isolation of the mono-pyrazolyl derivative $1 \mathbf{a}^{\prime}$, which will be useful as part of a pyrazole-based compounds' library for further investigations by our group, such as photophysical studies. Single crystals suitable for X-ray diffraction were collected from concentrated pentane and ethyl acetate:hexane (10:90) solutions for compounds $\mathbf{1}$ and $\mathbf{1 a}$, respectively. The single crystal X-ray diffraction study revealed that 1 crystallises in the triclinic $P(-1)$ space group, whereas 1a crystallises in the monoclinic $P\left(2_{1} / c\right)$ space group. The solid-state structures of $\mathbf{1}$ and $\mathbf{1 a}$ are shown in Figure 2, and the main crystallographic data and structure refinement parameters are summarised in the Supporting Information.

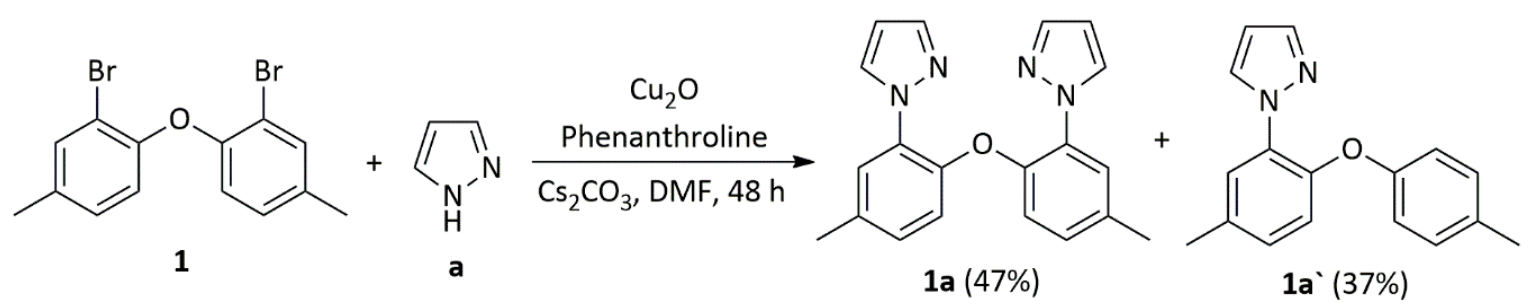

Scheme 1. Synthesis of DPEphos's pyrazolyl analogues. Reaction conditions: $\mathrm{Cu}_{2} \mathrm{O}(20 \mathrm{~mol} \%)$, phenanthroline (44 mol\%); 1 (1.0 eq.); a (3.2 eq.); $\mathrm{Cs}_{2} \mathrm{CO}_{3}$ (3.0 eq.); $\mathrm{DMF}(4 \mathrm{~mL}) ; 140{ }^{\circ} \mathrm{C} ; 48 \mathrm{~h}$.

The commercially available 4,5-dibromo-2,7-di-tert-butyl-9,9-dimethyl-9H-xanthene (2) was then employed as the substrate in the Ullmann coupling step to obtain the rigid pyrazolyl analogues of ${ }^{t} \mathrm{Bu}$-Xantphos, $\mathbf{2 a - 2} \mathbf{b}$ ' (Scheme 2). When the same reaction conditions described in Scheme 1 for the synthesis of compound 1a were applied, an incomplete conversion was observed for the reaction between 2 and a. Therefore, a slightly higher temperature $\left(160^{\circ} \mathrm{C}\right)$ was used, and as a result, the reaction of 2 with a as the nucleophile delivered the symmetrical bis-pyrazolyl analogue $2 \mathbf{a}$ in $41 \%$ isolated yield (Scheme 2). Single crystals of 2a suitable for X-ray diffraction were obtained by the slow diffusion of hexane into a concentrated dichloromethane (DCM) solution of $\mathbf{2 a}$. The solid-state structure of 2a is shown in Figure 2, and the main crystallographic data and structure refinement parameters are summarised in the Supporting Information (Table S5). In addition, as observed for the dibromo derivative $\mathbf{1}$, the mono-pyrazolyl debrominated byproduct $\mathbf{2} \mathbf{a}^{\prime}$ was also obtained. Unfortunately, the difficulty in chromatographic separation between $\mathbf{2 a}$ and $\mathbf{2} \mathbf{a}^{\prime}$ prevented an accurate quantification of $2 \mathbf{a}^{\prime}$. Nevertheless, a combined yield of $\sim 10 \%$ for four reactions was roughly calculated (Scheme 2). The use of a lower $\mathrm{Cu}_{2} \mathrm{O}$ loading $(10 \mathrm{~mol} \%)$ also led to an incomplete conversion. At this point, it is worth mentioning that the only reported example of an Ullmann reaction between a related aryl-bridged tetrabromo-xanthene scaffold and $1 \mathrm{H}$-pyrazole (a) was achieved by using a stoichiometric amount of $\mathrm{Cu}_{2} \mathrm{O}$ under microwave irradiation conditions [39]. 


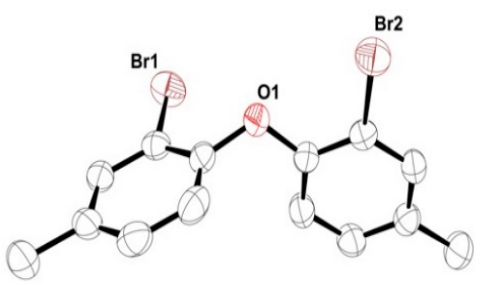

1

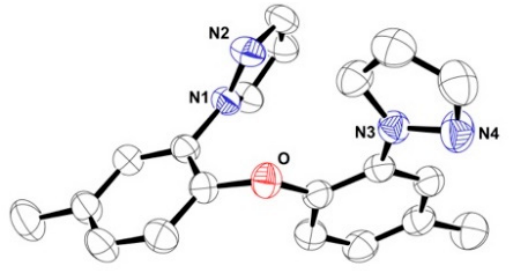

1a

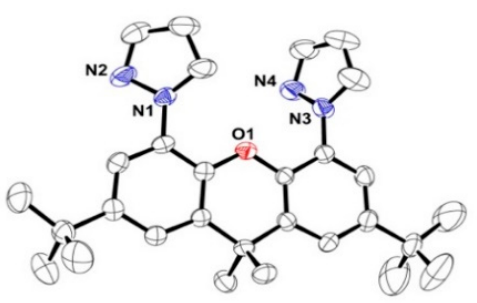

$2 \mathbf{a}$

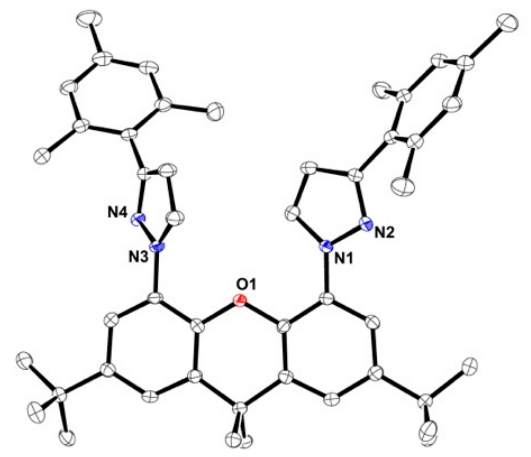

$2 \mathbf{b}$

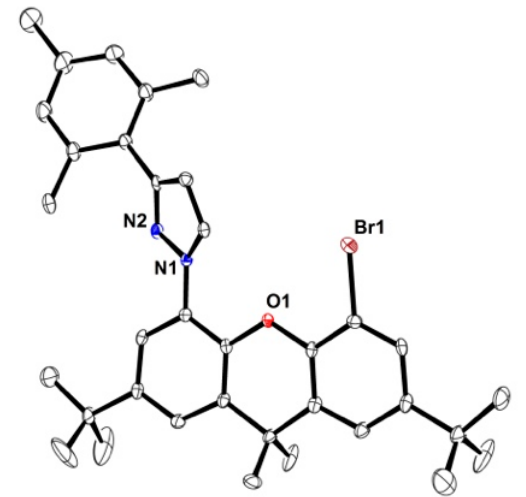

$2 \mathrm{~b}$

Figure 2. Molecular structures of $\mathbf{1}, \mathbf{1 a}, \mathbf{2 a}, \mathbf{2} \mathbf{b}$ and $\mathbf{2} \mathbf{b}^{\mathbf{}}$ with the key atoms labelled (thermal ellipsoids drawn at $50 \%$ probability). For clarity, hydrogen atoms have been omitted.

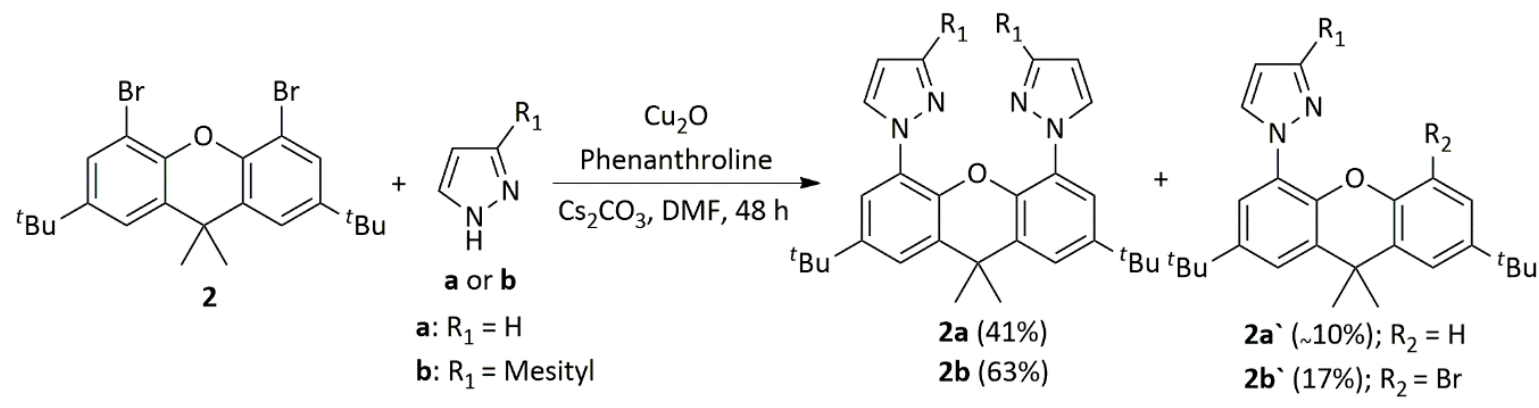

Scheme 2. Synthesis of pyrazolyl analogues of ${ }^{t} \mathrm{Bu}-X a n t p h o s$. Reaction conditions: $\mathrm{Cu}_{2} \mathrm{O}(10-20 \mathrm{~mol} \%)$; phenanthroline (22-44 mol\%); 2 (1.0 eq.); a or b (3.2 eq.); $\mathrm{Cs}_{2} \mathrm{CO}_{3}$ (3.0 eq.); $\mathrm{DMF}(4 \mathrm{~mL}) ; 140-160{ }^{\circ} \mathrm{C}$; $48 \mathrm{~h}$.

Surprisingly, a different scenario was perceived when 3-mesityl-1H-pyrazole (b) was used as the nucleophile. The synthesis of the symmetrical bis-mesitylpyrazolyl ligand $\mathbf{2} \mathbf{b}$ by the reaction of $\mathbf{2}$ with $\mathbf{b}$ was accomplished by using a lower $\mathrm{Cu}_{2} \mathrm{O}$ loading and a slightly lower temperature, leading to $\mathbf{2 b}$ in in an exceptionally higher yield (63\%). Another difference noticed for this reaction is that the debrominated mono-pyrazolyl byproduct was not obtained. Interestingly, the byproduct $\mathbf{2} \mathbf{b}^{\mathbf{}}$, isolated in $17 \%$ yield, retains the bromine atom in its structure (Scheme 2 ). This result clearly indicates that 3-mesityl-1H-pyrazole (b) is a better coupling partner for the Ullmann reaction than 
$1 \mathrm{H}$-pyrazole (a). Hence, the reaction proceeded under milder conditions, especially with lower $\mathrm{Cu}_{2} \mathrm{O}$ loading, providing both better selectivity and yield of $\mathbf{2 b}$ and preventing the $\mathrm{C}-\mathrm{Br}$ reduction after the first Ullmann coupling. Single crystals suitable for $\mathbf{X}$-ray diffraction of $\mathbf{2} \mathbf{b}$ and $\mathbf{2} \mathbf{b}^{\mathbf{}}$ were collected from concentrated $10 \%$ ethyl acetate and hexane solutions of the pure compounds. Both $\mathbf{2 b}$ and $\mathbf{2} \mathbf{b}^{\prime}$ crystallise in the triclinic $P(-1)$ space group. The solid-state structures are shown in Figure 2, and the main crystallographic data and the structure refinement parameters are summarised in the Supporting Information (Table S5). Moreover, two independent molecules were found in the asymmetric unit of

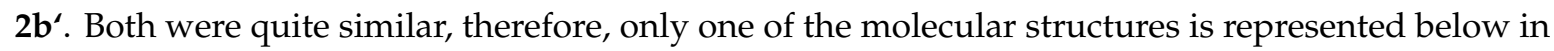
Figure 2.

The isolation of the byproduct derivative $\mathbf{2} \mathbf{b}^{\mathbf{A}}$ expands the scope of the reaction, since it allows the synthesis of hybrid compounds through a second coupling reaction with different nucleophiles. In order to demonstrate this, $\mathbf{2} \mathbf{b}^{\mathbf{}}$ was treated with $1 \mathrm{H}$-imidazole (c) under similar conditions described for the synthesis of $\mathbf{2} \mathbf{b}$. As a result, the hybrid $\mathbf{2} \mathbf{b}^{\mathbf{\prime}} \mathbf{c}$ was obtained in $78 \%$ isolated yield (Scheme 3 ).

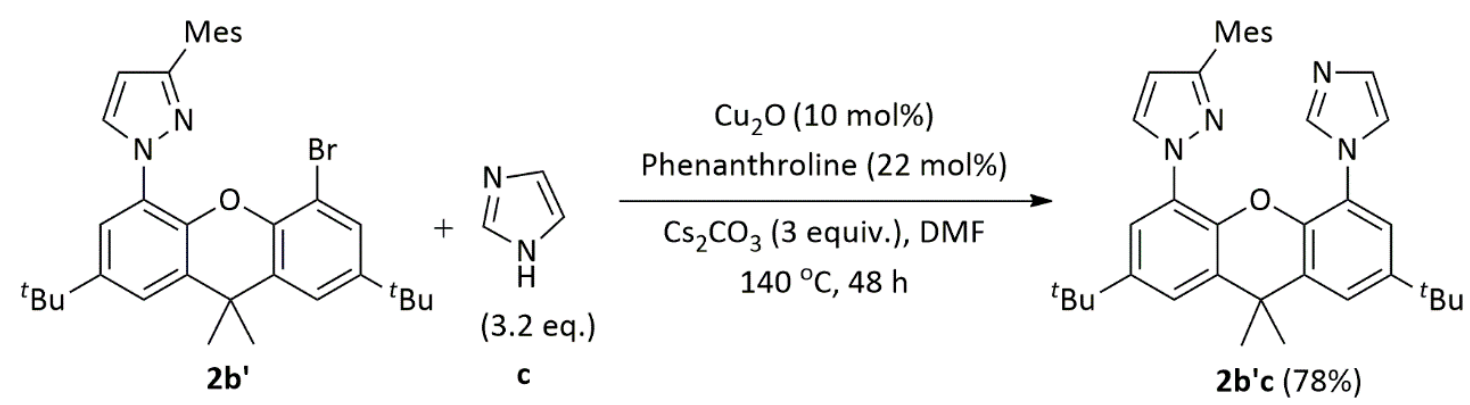

Scheme 3. Synthesis of hybrid analogue $\mathbf{2} \mathbf{b}^{\prime} \mathbf{c}$ from $\mathbf{2} \mathbf{b}^{\prime}$.

In addition, a selanyl-pyrazolyl hybrid analogue $2 \mathbf{a}^{\prime} \mathbf{d}$ was synthesized using a $\mathrm{C}-\mathrm{H}$ activation, protocol recently described in the literature [40]. Using both $5 \mathrm{~mol} \%$ of $\mathrm{PdCl}_{2}$ and $\mathrm{CuCl}_{2}$, the reaction between $\mathbf{2} \mathbf{a}^{\prime}$ and diphenyl diselenide (d) in DMSO delivered the hybrid analogue $\mathbf{2} \mathbf{a}^{\mathbf{\prime}} \mathbf{d}$ in $58 \%$ isolated yield (Scheme 4).

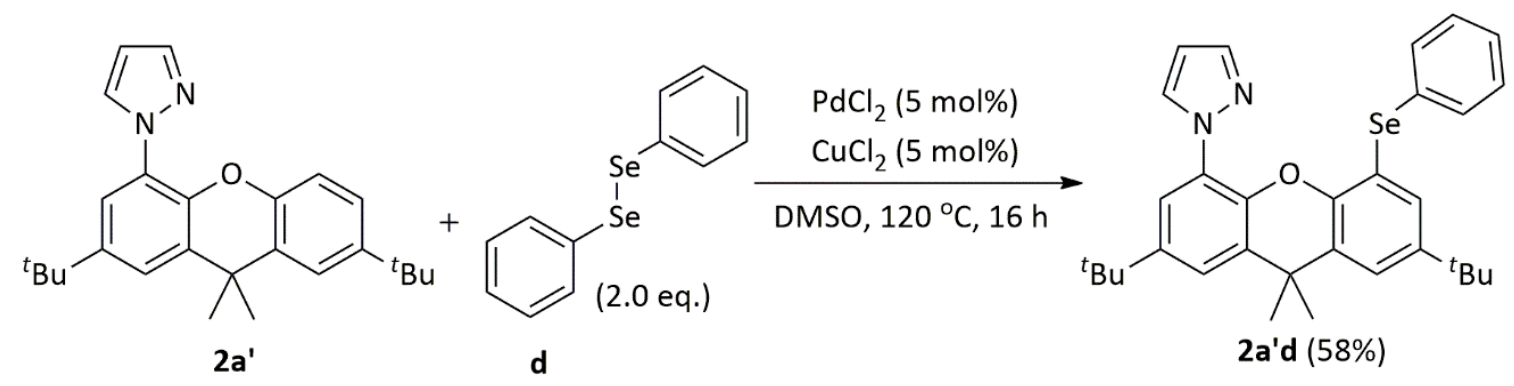

Scheme 4. Synthesis of hybrid analogue $2 \mathbf{a}^{\prime} \mathbf{d}$ from $2 \mathbf{a}^{\prime}$ via a C-H activation protocol.

With the new pyrazolyl analogues in hand, we moved to their evaluation as ligands in the SM cross-coupling reaction of aryl halides and aryl boronic acids using $\mathrm{Pd}(\mathrm{OAc})_{2}$ as the palladium source. To this end, we initially employed the symmetrical bis-pyrazolyl analogue $2 \mathbf{a}$ as the ligand in the cross-coupling between 4-bromotoluene and phenylboronic acid, chosen as a model of the Suzuki-Miyaura reaction (Scheme 5). 


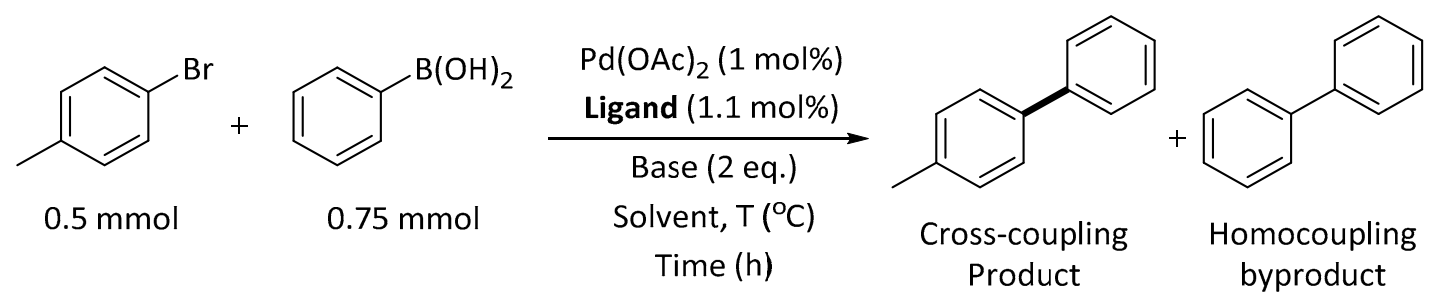

Scheme 5. Model SM reaction used for optimisation and ligand evaluation.

We began optimising the reaction with $\mathrm{Pd}(\mathrm{OAc})_{2} / \mathbf{2 a}$ by screening different solvent and base combinations (Scheme 5 and Table 1). Initially, we used $\mathrm{KOH}$ as base and methanol as solvent based on our studies for the SM cross-coupling reaction of aryl bromides with an alkyl palladium complex containing 1,1-(2,2'-oxybis(ethane-2,1-diyl)-bis(3,5-dimethyl-1H-pyrazole) [36]. Under these conditions, the cross-coupling product was obtained in $66 \%$ yield (Table 1, entry 1 ). It is important to mention that a control experiment under ligand-free conditions using $\mathrm{KOH}$ as base and methanol as solvent gave high conversion but low yield for the cross-coupling product $(\sim 17 \%)$. Therefore, we investigated other common base/solvent combinations for the SM cross-coupling reaction (Table 1 , entries 2-4), and we were pleased to verify that the use of an inexpensive base such as $\mathrm{K}_{2} \mathrm{CO}_{3}$ in $\mathrm{DMF}$ as the solvent, after $6 \mathrm{~h}$ of magnetic stirring at $80^{\circ} \mathrm{C}$, delivers the cross-coupling product in almost quantitative yield (Table 1, entry 4). Biphenyl homocoupling (HC) byproduct was obtained in very low yield $\left(<2 \%\right.$ for $\left.\mathrm{Pd}(\mathrm{OAc})_{2}\right)$ for all the reaction conditions evaluated. The use of ethereal solvents provided very low yields of the cross-coupling product (Table 1, entries 2,6-8), and most of the 4-bromotoluene converted was reduced to toluene. A further investigation of different Pd sources (Table 1, entries 4,9-11) confirmed our initial choice, $\mathrm{Pd}(\mathrm{OAc})_{2}$, as the best pre-catalyst under the reaction conditions employed.

Table 1. Solvent, base and Pd source effects on the model SM cross-coupling (CC) reaction using ligand 2a. ${ }^{\text {a }}$

\begin{tabular}{|c|c|c|c|c|c|c|}
\hline Entry & [Pd] (1 mol\%) & Base & Solvent & $\begin{array}{c}\text { Conversion } \\
\left(_{(\%)^{b}}^{b}\right.\end{array}$ & $\begin{array}{l}\text { CC Yield } \\
(\%)^{b}\end{array}$ & $\begin{array}{c}\text { HC Yield } \\
(\%)^{c}\end{array}$ \\
\hline 1 & $\mathrm{Pd}(\mathrm{OAc})_{2}$ & $\mathrm{KOH}$ & $\mathrm{MeOH}$ & 74 & 66 & 1 \\
\hline 2 & $\mathrm{Pd}(\mathrm{OAc})_{2}$ & $\mathrm{~K}_{3} \mathrm{PO}_{4}$ & Dioxane & 48 & 7 & 1 \\
\hline 3 & $\mathrm{Pd}(\mathrm{OAc})_{2}$ & $\mathrm{Cs}_{2} \mathrm{CO}_{3}$ & DMF & 87 & 61 & 1 \\
\hline 4 & $\mathrm{Pd}(\mathrm{OAc})_{2}$ & $\mathrm{~K}_{2} \mathrm{CO}_{3}$ & DMF & 99 & 98 & 1 \\
\hline 5 & $\mathrm{Pd}(\mathrm{OAc})_{2}$ & $\mathrm{~K}_{2} \mathrm{CO}_{3}$ & $\mathrm{MeOH}$ & 75 & 44 & 1 \\
\hline 6 & $\mathrm{Pd}(\mathrm{OAc})_{2}$ & $\mathrm{~K}_{2} \mathrm{CO}_{3}$ & THF:MeOH ${ }^{\mathrm{d}}$ & 65 & 4 & 2 \\
\hline 7 & $\mathrm{Pd}(\mathrm{OAc})_{2}$ & $\mathrm{~K}_{2} \mathrm{CO}_{3}$ & $\mathrm{THF}^{\mathrm{d}}$ & 49 & 1 & 2 \\
\hline 8 & $\mathrm{Pd}(\mathrm{OAc})_{2}$ & $\mathrm{~K}_{2} \mathrm{CO}_{3}$ & Dioxane & 48 & 2 & 1 \\
\hline 9 & $\mathrm{PdCl}_{2}$ & $\mathrm{~K}_{2} \mathrm{CO}_{3}$ & DMF & 97 & 88 & 4 \\
\hline 10 & $\mathrm{PdCl}_{2}(\mathrm{COD})^{\mathrm{e}}$ & $\mathrm{K}_{2} \mathrm{CO}_{3}$ & $\mathrm{DMF}$ & 72 & 55 & 3 \\
\hline 11 & $\mathrm{PdCl}_{2}(\mathrm{PhCN})_{2}$ & $\mathrm{~K}_{2} \mathrm{CO}_{3}$ & DMF & 93 & 92 & 2 \\
\hline
\end{tabular}

${ }^{a}$ Reaction conditions: solvent $(4 \mathrm{~mL}), 80^{\circ} \mathrm{C}, 6$ h. For other conditions see Scheme $5 .{ }^{\mathrm{b}}$ Determined by GC, based on 4-bromotoluene. ${ }^{c}$ GC yield for the biphenyl homocoupling byproduct, based on phenylboronic acid. ${ }^{\mathrm{d}} \mathrm{THF}=$ tetrahydrofuran. ${ }^{\text {e }} \mathrm{COD}=1,5$-cyclooctadiene.

Then, we investigated the effect of temperature. When the reaction was performed at room temperature, the cross-coupling product was obtained in low yield (Table 2, entry 1). Hence, higher reaction temperatures were evaluated, leading to an improvement in both conversion and yield, with the best results being achieved at $80{ }^{\circ} \mathrm{C}$ (Table 2, entries 2 and 3). On the other hand, a further rise in the temperature to $110^{\circ} \mathrm{C}$ led to a decrease in both conversion and yield, indicating partial catalyst decomposition (Table 2, entry 4). A lower catalyst loading of $0.5 \mathrm{~mol} \%$ also led to a lower conversion and yield (Table 2, entry 5). Therefore, the SM cross-coupling reaction between 4-bromotoluene and 
phenylboronic acid proceeds smoothly employing $1 \mathrm{~mol} \%$ of $\mathrm{Pd}(\mathrm{OAc})_{2} / 2 \mathrm{a}$ in the presence of $\mathrm{K}_{2} \mathrm{CO}_{3}$, in DMF as solvent at $80^{\circ} \mathrm{C}$ for $6 \mathrm{~h}$.

Table 2. Temperature effect on the model SM cross-coupling reaction using ligand 2a. ${ }^{\text {a }}$

\begin{tabular}{cccccc}
\hline Entry & Temp. $\left({ }^{\circ} \mathbf{C}\right)$ & Time (h) & Conversion (\%) & CC Yield (\%) $^{\mathbf{b}}$ & HC Yield (\%) $^{\mathbf{c}}$ \\
\hline 1 & 25 & 24 & 73 & 59 & 1 \\
2 & 50 & 12 & 92 & 70 & 1 \\
3 & 80 & 6 & 99 & 98 & 1 \\
4 & 110 & 3 & 90 & 75 & 1 \\
5 & 80 & 12 & 87 & $82^{\mathrm{d}}$ & 1 \\
\hline
\end{tabular}

${ }^{a}$ Reaction conditions: $\mathrm{K}_{2} \mathrm{CO}_{3}$ (2 eq.) and DMF $(4 \mathrm{~mL})$. For other conditions, see Scheme $5 .{ }^{\mathrm{b}}$ Determined by GC, based on 4-bromotoluene. ${ }^{\mathrm{C}} \mathrm{GC}$ yield for the biphenyl homocoupling byproduct, based on phenylboronic acid.

d $0.5 \mathrm{~mol} \% \mathrm{Pd}(\mathrm{OAc})_{2} / 2$.

Next, we employed the optimised reaction conditions using $\mathbf{2 a}$ for the evaluation of the other pyrazole-based compounds $\mathbf{1} \mathbf{a}, \mathbf{1} \mathbf{a}^{\prime}, \mathbf{2} \mathbf{a}^{\prime}, \mathbf{2} \mathbf{b}, \mathbf{2} \mathbf{b}^{\mathbf{\prime}} \mathbf{c}$, and $\mathbf{2} \mathbf{a}^{\mathbf{\prime}} \mathbf{d}$ as ligands in our model Suzuki-Miyaura reaction. The results are summarised in Table 3 . The symmetrical ligands $\mathbf{2} \mathbf{a}$ and $\mathbf{2} \mathbf{b}$, and the hybrid analogue $\mathbf{2} \mathbf{b}^{\prime} \mathbf{c}$ were found the most active and selective among all the new ligands evaluated, providing the corresponding cross-coupling product in excellent yields (98-99\%) (Table 3, entries 1-3). A slightly lower conversion (87\%) and yield (86\%) was observed with the mono-pyrazolyl ligand $\mathbf{2} \mathbf{a}^{\prime}$ (Table 3, entry 4). In contrast, the use of the hybrid ligand $\mathbf{2} \mathbf{a}^{\prime} \mathbf{d}$ did not deliver an active catalyst system (Table 3, entry 5), probably due to the C-Se bond cleavage by $\mathrm{Pd}$, as it is well known that majority of the C-Se bonds are very sensitive towards $\mathrm{Pd}$ and undergo oxidative addition with Pd metal [41]. Likewise, the use of flexible ligands 1a and 1a' provided only low yields of the cross-coupling products (Table 3 , entry 6 and 7). We hypothesise that the high conformational freedom around the central oxygen atom of ligand 1a and 1a' prevents effective chelation with Pd, leading to a much less efficient catalyst compared to those derived from the ligands with the rigid xanthene backbone. It is also important to mention that under the optimised reaction conditions, lower conversion and yield were obtained using the Xantphos diphosphine ligand (Table 3, entry 9 compared to entries 1-3).

Table 3. Screening of pyrazolyl ligands for the SM cross-coupling reaction under optimised reaction conditions. $^{\mathrm{a}}$

\begin{tabular}{ccccc}
\hline Entry & Ligand & Conversion $\mathbf{( \% )} \mathbf{b}^{\mathbf{b}}$ & CC Yield (\%) $^{\mathbf{b}}$ & HC Yield (\%) $^{\mathbf{c}}$ \\
\hline 1 & $\mathbf{2 a}$ & 99 & 98 & 1 \\
2 & $\mathbf{2 b}$ & $>99$ & 98 & 1 \\
3 & $\mathbf{2 \mathbf { b } ^ { \prime } \mathbf { c }}$ & 99 & 98 & 1 \\
4 & $\mathbf{2 \mathbf { a } ^ { \prime }}$ & 87 & 86 & 1 \\
5 & $\mathbf{2 \mathbf { a } ^ { \prime } \mathbf { d }}$ & 46 & 5 & 1 \\
6 & $\mathbf{1 a}$ & 83 & 47 & 1 \\
7 & $\mathbf{1 a}$ & 62 & 29 & 1 \\
8 & - & 68 & 44 & 2 \\
9 & Xantphos & 84 & 77 & 6 \\
\hline
\end{tabular}
a Reaction conditions: $\mathrm{K}_{2} \mathrm{CO}_{3}$ (2 eq.), DMF ( $4 \mathrm{~mL}$ ), and $6 \mathrm{~h}$. For other conditions, see Scheme $5 .{ }^{\mathrm{b}}$ Determined by
$\mathrm{GC}$, based on 4 -bromotoluene. ${ }^{\mathrm{c}} \mathrm{GC}$ yield for the biphenyl homocoupling byproduct, based on phenylboronic acid.

Finally, we evaluated the scope of the SM cross-coupling reaction using the $\mathrm{Pd}(\mathrm{OAc})_{2} / 2$ a catalytic system under optimised conditions, employing different haloarenes and arylboronic acids with varying electronic and steric characteristics. The results are summarised in Table 4. In general, both electron rich and poor bromoarenes were well tolerated, providing the corresponding cross-coupling products with phenylboronic acid in good to excellent yields (Table 4, entries 1-5). The reactions of an electron-rich and an electron-poor arylboronic acid with 4-bromotoluene were also tested. In both cases, the coupling products were obtained in good yields of approximately $80 \%$ (Table 4, entries 6 and 7). Two other 
combinations of arylbromides and arylboronic acids of opposite electronic characters were also evaluated, and no considerable effect in the yield range for the coupling product was observed (Table 4, entries 8 and 9). Usually, electron-withdrawing substituents on the aryl halides and electron-donating substituents on the arylboronic acids facilitate smooth SM cross-coupling reactions, due to the easier oxidative addition and transmetallation steps, respectively [42]. Therefore, the $\mathrm{Pd}(\mathrm{OAc})_{2} / \mathbf{2 a}$ catalytic system is not severely influenced by the electronic nature of the $p$-substituents on the coupling partners. However, the catalytic system is sensitive to steric effects. The steric hindrance tolerance was evaluated by employing ortho-substituted substrates. The introduction of methyl substituents on this position, on either of the coupling partners, led to a decreased yield of the cross-coupling products (Table 4, entries 10-12). The similarities in the results obtained with the introduction of a sole ortho methyl group on the arylbromide ( $54 \%$ yield, Table 4 , entry 10 ) and on the arylboronic acid ( $58 \%$ yield, Table 4 , entry 11 ) indicate that the oxidative addition step is not severely affected, and that the observed decreased yield is probably due to a more difficult transmetallation or reductive elimination step.

Table 4. Substrate scope for the SM reaction using ligand 2a under optimised reaction conditions. ${ }^{\text {a }}$

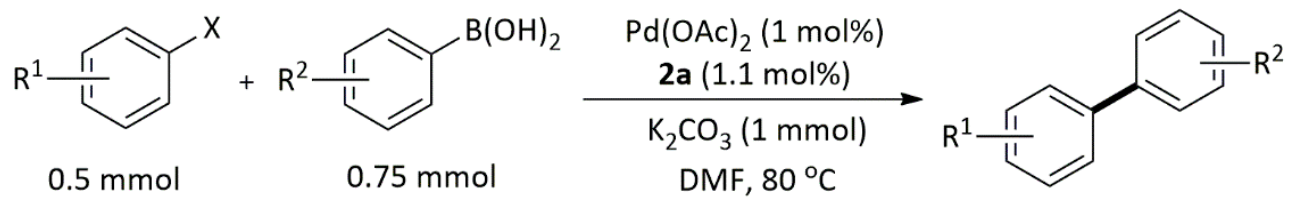

\begin{tabular}{ccccc}
\hline Entry & $\mathbf{R}^{\mathbf{1}}$ & $\mathbf{X}$ & $\mathbf{R}^{\mathbf{2}}$ & Yield (\%) $^{\mathbf{b}}$ \\
\hline 1 & $4-\mathrm{Me}$ & $\mathrm{Br}$ & $\mathrm{H}$ & 94 \\
2 & $4-\mathrm{CF}_{3}$ & $\mathrm{Br}$ & $\mathrm{H}$ & 82 \\
3 & $4-\mathrm{Ac}$ & $\mathrm{Br}$ & $\mathrm{H}$ & 91 \\
4 & $4-\mathrm{Ome}$ & $\mathrm{Br}$ & $\mathrm{H}$ & 91 \\
5 & $2-\mathrm{bromonaphthalen}$ & $\mathrm{H}$ & 82 \\
6 & $4-\mathrm{Me}$ & $\mathrm{Br}$ & $4-\mathrm{OMe}$ & 78 \\
7 & $4-\mathrm{Me}$ & $\mathrm{Br}$ & $4-\mathrm{Ac}$ & 73 \\
8 & $4-\mathrm{OMe}$ & $\mathrm{Br}$ & $4-\mathrm{Ac}$ & 81 \\
9 & $4-\mathrm{Ac}$ & $\mathrm{Br}$ & $\mathrm{H}$ & 58 \\
10 & $2-\mathrm{Me}$ & $\mathrm{Br}$ & $2-\mathrm{Me}$ & 54 \\
11 & $4-\mathrm{Me}$ & $\mathrm{Br}$ & $\mathrm{Br}-\mathrm{diMe}$ & 76 \\
12 & $4-\mathrm{Me}$ & $\mathrm{Br}$ & 80 \\
13 & $4-\mathrm{CF}$ & $\mathrm{I}$ & $\mathrm{H}$ & 75 \\
14 & $4-\mathrm{OMe}$ & $\mathrm{I}$ & $\mathrm{H}$ & $3{ }^{\mathrm{c}}$ \\
15 & $4-\mathrm{Ac}$ & $\mathrm{Cl}$ & $\mathrm{H}$ & 25 \\
\hline
\end{tabular}

${ }^{\mathrm{a}}$ DMF $(4 \mathrm{~mL})$ and overnight. ${ }^{\mathrm{b}}$ Isolated yields (average of two reactions after complete conversion). ${ }^{\mathrm{c}}$ Ligand-free conditions, GC yield based on 4 -Cl-acetophenone after $24 \mathrm{~h}$ ( $4 \%$ conversion).

Even though aryl iodides are generally more active than aryl bromides due to the easier oxidative addition step, we observed slightly lower yields for aryl iodides (80\% vs. 91\%, entries 14 and 4; and $78 \%$ vs. $82 \%$, entries 13 and 2). Since the homocoupling byproduct was obtained in less than $2 \%$ for both aryl iodides, we assume that a dehalogenation side reaction must be occurring in higher extension for those substrates, being possibly responsible for the lower isolated yields. As far as the aryl chlorides are concerned, we were pleased to see that $p$-chloroacetophenone reacted smoothly under optimised conditions as well (Table 4, entry 15), and even the deactivated $p$-chlorotoluene led to the cross-coupling product in $25 \%$ yield (Table 4, entry 17). A control experiment for the coupling of $p$-chloroacetophenone with phenylboronic acid under ligand-free conditions gave only $4 \%$ conversion and 3\% yield of the cross-coupling product after $24 \mathrm{~h}$ (Table 4, entry 16). Although we were not able to isolate the corresponding Pd complexes, the in situ formation of coordinated PdL active species is 
evinced when the results obtained with $\mathrm{Pd}(\mathrm{OAc})_{2} / \mathbf{2 a}$ catalytic system and under ligand-free conditions are compared, clearly demonstrating the positive effect of the ligand on the cross-coupling reaction.

\section{Materials and Methods}

\subsection{Materials}

All reagents were purchased from commercial suppliers and used without further purification. p-tolyl ether, 2, and aryl halides were purchased from Sigma Aldrich. Aryl boronic acids were purchased from Alfa Aesar. The Ullmann and Suzuki-Miyaura coupling reactions were performed using standard Schlenk tube techniques under argon atmosphere. The solvents employed on these reactions were degassed by purging with argon for 20 to $30 \mathrm{~min}$ prior to each experiment. The progress of the reaction was monitored by GC. The GC analyses were performed using a Shimadzu GC-2010 plus equipment equipped with a $30 \mathrm{~m}$ DB-17 column and FID detector, while the GC/MS measurements were performed using a Shimadzu GC/MS-QP2010 SE, (EI $70 \mathrm{eV}$ ) equipped with a $30 \mathrm{~m}$ Rxi-1ms ${ }^{\circledR}$ column. Column chromatography purifications were performed using silica gel (230-400 mesh) and mixtures of hexanes/ethyl acetate as eluents. The names of all the compounds were assigned using ChemBioDraw Ultra 12.0 software (CambridgeSoft, Cambridge, UK).

Nuclear magnetic resonance (NMR) spectra were recorded in $\mathrm{CDCl}_{3}$ solutions, unless noted otherwise, on MR-400-Varian $400 \mathrm{MHz}$, Bruker Avance-IIIHD $400 \mathrm{MHz}$ and Bruker Fourier $300 \mathrm{MHz}$ instruments. Infrared (IR) spectra were obtained using attenuated total reflectance (ATR) technique, on a Bruker Alpha- $P$ spectrometer, with scans between 4000 and $650 \mathrm{~cm}^{-1}$, with $4 \mathrm{~cm}^{-1}$ resolution. The compounds were analysed in their pure forms and the maximum absorbing frequencies are reported in $\mathrm{cm}^{-1}$. The high resolution mass spectrometry (HRMS) data were obtained on a Waters micromass Q-ToF microTM instrument, operating on positive mode and the melting points were measured on a Quimis ${ }^{\circledR}$ instrument and are uncorrected.

\subsection{Synthesis of Pyrazolyl Analogues of DPEphos and ${ }^{t} B u-X a n t p h o s$}

\subsubsection{Dibromination of $p$-Tolyl Ether (Preparation of $\mathbf{1}$ )}

To a stirring solution of $\mathrm{NH}_{4} \mathrm{OAc}(20 \mathrm{~mol} \%, 2 \mathrm{mmol})$ and $p$-tolyl ether (1 eq., $\left.10 \mathrm{mmol}\right)$ in $35 \mathrm{~mL}$ of $\mathrm{CH}_{3} \mathrm{CN}$, was added NBS (2.5 eq., $25 \mathrm{mmol}$ ) portionwise over a period of 10-15 min. The reaction mixture was kept under magnetic stirring at room temperature overnight $(16 \mathrm{~h})$. After this period, the crude reaction mixture was taken up in ethyl acetate and washed with distilled water ( $3 \mathrm{x})$, followed by drying over anhydrous $\mathrm{MgSO}_{4}$ and solvent removal under reduced pressure. The crude mixture was purified by using flash silica gel column chromatography (10\% ethyl acetate and hexanes). Recrystallisation in n-pentane furnished colourless crystals of dibrominated product (1) in $68 \%$ yield.

4,4'-oxybis(3-bromo-1-methylbenzene) (1). White crystalline solid (m.p. $\left.=74-75{ }^{\circ} \mathrm{C}\right) ;{ }^{1} \mathrm{H}-\mathrm{NMR}$ $\left(400 \mathrm{MHz}, \mathrm{CDCl}_{3}\right) \delta 7.45(\mathrm{~d}, J=2.1 \mathrm{~Hz}, 2 \mathrm{H}, \mathrm{Ar}), 7.03(\mathrm{ddd}, J=8.3,2.1,0.6 \mathrm{~Hz}, 2 \mathrm{H}, \mathrm{Ar}), 6.72(\mathrm{~d}, J=8.3 \mathrm{~Hz}$, 2H, Ar), 2.32 (s, 6H, CH $)_{3} ;{ }^{13} \mathrm{C}-\mathrm{NMR}\left(100 \mathrm{MHz}, \mathrm{CDCl}_{3}\right) \delta 151.41$ (Ar-C), 134.97 (Ar-C), 134.25 (Ar-CH), 129.30 (Ar-CH), 119.29 (Ar-CH), 113.89 (Ar-C), $20.56\left(\mathrm{CH}_{3}\right)$; IR (ATR): 1477, 1247, 1041, 826, 808; HRMS (ESI-TOF): $m / z$ calcd for $\mathrm{C}_{14} \mathrm{H}_{12} \mathrm{Br}_{2} \mathrm{ONa}(\mathrm{M}+\mathrm{Na})^{+} ; 376.9153$, found 376.9140 .

\subsubsection{Preparation of 3-Mesityl-1H-pyrazole}

3-Mesityl-1H-pyrazole was prepared through adapted literature procedures $[43,44]$. To a round bottom flask containing $130 \mathrm{~mL}$ of toluene maintained at $0{ }^{\circ} \mathrm{C}$ on an ice bath, Na metal ( 2 eq., $200 \mathrm{mmol}$ ) was added in portions, followed by dropwise addition of 2,4,6-trimethyl acetophenone ( 1 eq., $100 \mathrm{mmol}$ ) and the resulting suspension was allowed to stir for $1.5 \mathrm{~h}$. To this yellowish reaction mixture, ethyl formate ( 3.4 eq., $340 \mathrm{mmol}$ ) was added dropwise over a period of 15-20 min and the reaction mixture was left overnight for stirring at room temperature. After, the reaction was cooled to $0{ }^{\circ} \mathrm{C}$ on an ice bath and distilled water was added dropwise to quench the unreacted Na metal 
(Caution!). After all the unreacted Na metal was quenched, additional $200 \mathrm{~mL}$ of distilled water were added to the reaction flask and the resulting suspension was kept under magnetic stirring for one hour. The resulting mixture was transferred to a separatory funnel, the phases were separated, and the aqueous layer was washed with hexanes (3x). The first organic phase and washes contain mainly byproducts and can be discarded. The aqueous layer was then acidified with $10 \% \mathrm{HCl}$, followed by extraction with DCM (3x). Finally, the combined organic phases were dried over $\mathrm{MgSO}_{4}$ and evaporated under reduced pressure, furnishing a yellowish solid product. This crude product without further purification was treated with hydrazine hydrochloride $(1.5 \mathrm{eq} .150 \mathrm{mmol})$ in ethanol $(350 \mathrm{~mL})$ and refluxed for $2.5 \mathrm{~h}$. After, the reaction mixture was concentrated under reduced pressure to half of its initial volume, followed by addition of $2 \mathrm{M} \mathrm{NaOH}$ solution (1:1 ratio of reaction mixture and $\mathrm{NaOH}$ solution). The aqueous layer was extracted with DCM (3x). The combined organic phases were dried over $\mathrm{MgSO}_{4}$ and concentrated under reduced pressure. Recrystallisation from hot hexane furnished yellowish crystals of the desired compound in $35 \%$ overall yield. The spectroscopic properties of the compound were consistent with the data available in the literature [44].

3-Mesityl-1H-pyrazole (b). Yellow crystalline needles; ${ }^{1} \mathrm{H}-\mathrm{NMR}\left(400 \mathrm{MHz}, \mathrm{CDCl}_{3}\right) \delta 10.77$ (br s, $1 \mathrm{H}$, $\mathrm{NH}), 7.53(\mathrm{~d}, J=1.7 \mathrm{~Hz}, \mathrm{Pz}), 6.91(\mathrm{~s}, 2 \mathrm{H}, \mathrm{Mes}), 6.19(\mathrm{~d}, J=1.5 \mathrm{~Hz}, 1 \mathrm{H}, \mathrm{Pz}), 2.34\left(\mathrm{~s}, 3 \mathrm{H}, \mathrm{Mes}-\mathrm{CH}_{3}\right), 2.06(\mathrm{~s}$, 6H, Mes- $\left.\mathrm{CH}_{3}\right) ;{ }^{13} \mathrm{C}-\mathrm{NMR}\left(100 \mathrm{MHz}, \mathrm{CDCl}_{3}\right) \delta 143.93$ (Pz-C), 138.01 (Mes-C), 137.71 (Pz-CH), 135.75

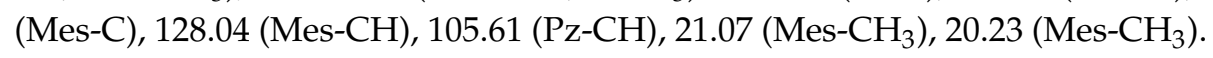

\subsubsection{Synthesis of Ligands $\mathbf{1 a}$ and $\mathbf{1} \mathbf{a}^{\mathbf{1}}$}

A resealable Schlenk flask evacuated and back-filled with argon (3x) was charged with $\mathrm{Cu}_{2} \mathrm{O}$ (21.5 mg, $0.15 \mathrm{mmol}$ ), 1,10-phenanthroline ( $59.5 \mathrm{mg}, 0.33 \mathrm{mmol}), \mathbf{1}$ (267.1 mg, $0.75 \mathrm{mmol}$ ), $1 \mathrm{H}$-pyrazole (a) $(163.5 \mathrm{mg}, 2.4 \mathrm{mmol})$, and $\mathrm{Cs}_{2} \mathrm{CO}_{3}(733.1 \mathrm{mg}, 2.25 \mathrm{mmol})$, followed by $4 \mathrm{~mL}$ of degassed DMF. The Schlenk was sealed under inert atmosphere and the reaction was left under magnetic stirring for $20 \mathrm{~h}$ at $140{ }^{\circ} \mathrm{C}$, in an oil bath. Then the reaction was cooled to room temperature and filtered through a short plug of celite, followed by washing with $\mathrm{CH}_{2} \mathrm{Cl}_{2}$. The filtrate was washed with distilled water (3x) and the organic layer was dried over $\mathrm{MgSO}_{4}$, filtered and concentrated under reduced pressure. The residue was subjected to column chromatography purification using $10 \%$ AcOEt in hexanes as eluent, furnishing bis-pyrazole 1a in $47 \%$ yield along with the mono-pyrazole byproduct 1 $\mathbf{a}^{\prime}$ in $37 \%$ yield.

1,1'-(oxybis(3-methyl-6,1-phenylene))bis(1H-pyrazole)) (1a). White crystalline solid (m.p. $=124-125$ $\left.{ }^{\circ} \mathrm{C}\right) ;{ }^{1} \mathrm{H}-\mathrm{NMR}\left(400 \mathrm{MHz}, \mathrm{CDCl}_{3}\right) \delta 7.88(\mathrm{~d}, J=2.5 \mathrm{~Hz}, 2 \mathrm{H}, \mathrm{Pz}), 7.68(\mathrm{~d}, J=1.7 \mathrm{~Hz}, 2 \mathrm{H}, \mathrm{Ar}), 7.62(\mathrm{~d}$, $J=1.7 \mathrm{~Hz}, 2 \mathrm{H}, \mathrm{Pz}), 7.03(\mathrm{ddd}, J=8.4,1.5,0.6 \mathrm{~Hz}, 2 \mathrm{H}, \mathrm{Ar}), 6.85(\mathrm{~d}, J=8.4 \mathrm{~Hz}, 2 \mathrm{H}, \mathrm{Ar}), 6.36(\mathrm{dd}, J=2.4$, $1.9 \mathrm{~Hz}, 2 \mathrm{H}, \mathrm{Pz}), 2.36\left(\mathrm{~s}, 6 \mathrm{H}, \mathrm{CH}_{3}\right) ;{ }^{13} \mathrm{C}-\mathrm{NMR}\left(100 \mathrm{MHz}, \mathrm{CDCl}_{3}\right) \delta 145.71$ (Ar-C), 140.35 (Pz-CH), 134.70 (Ar-C), 131.41 (Pz-CH), 131.07 (Ar-C), 129.07 (Ar-CH), 126.22 (Ar-CH), 119.30 (Ar-CH), 107.05 (Pz-CH), $20.81\left(\mathrm{CH}_{3}\right)$; IR $v_{\max }$ (neat): 1497, 1221, 1034, 809, 761; HRMS (ESI-TOF): $m / z$ calcd for $\mathrm{C}_{20} \mathrm{H}_{18} \mathrm{~N}_{4} \mathrm{ONa}$ $(\mathrm{M}+\mathrm{Na})^{+}: 353.1378$, found 353.1369 .

1-(5-methyl-2-(p-tolyloxy)phenyl)-1H-pyrazole (1a'). Pale yellow liquid; ${ }^{1} \mathrm{H}-\mathrm{NMR}\left(400 \mathrm{MHz}, \mathrm{CDCl}_{3}\right)$ $\delta 8.09(\mathrm{~d}, J=2.5 \mathrm{~Hz}, 1 \mathrm{H}, \mathrm{Pz}), 7.73(\mathrm{~d}, J=1.8 \mathrm{~Hz}, 1 \mathrm{H}, \mathrm{Ar}), 7.68(\mathrm{~d}, J=1.5 \mathrm{~Hz}, 1 \mathrm{H}, \mathrm{Pz}), 7.09(\mathrm{~d}, J=8.3 \mathrm{~Hz}$, $2 \mathrm{H}, \mathrm{Ar}), 7.06(\mathrm{dd}, J=8.5,1.9 \mathrm{~Hz}, 1 \mathrm{H}, \mathrm{Ar}), 6.93(\mathrm{~d}, J=8.3 \mathrm{~Hz}, 1 \mathrm{H}, \mathrm{Ar}), 6.85(\mathrm{~d}, J=8.5 \mathrm{~Hz}, 2 \mathrm{H}, \mathrm{Ar})$, $6.37(\mathrm{t}, J=2.4 \mathrm{~Hz}, 1 \mathrm{H}, \mathrm{Pz}), 2.40\left(\mathrm{~s}, 3 \mathrm{H}, \mathrm{CH}_{3}\right), 2.31\left(\mathrm{~s}, 3 \mathrm{H}, \mathrm{CH}_{3}\right) .{ }^{13} \mathrm{C}-\mathrm{NMR}\left(100 \mathrm{MHz}, \mathrm{CDCl}_{3}\right) \delta 154.76$ (Ar-C), 145.55 (Ar-C), 140.24 (Pz-CH), 134.26 (Ar-C), 132.70 (Ar-C), 131.78 (Ar-C), 131.12 (Ar-C), 130.20 (Ar-CH), 128.27 (Pz-CH), 125.35 (Ar-CH), 120.47 Ar-CH), 117.69 (Ar-CH), $106.67(\mathrm{Pz}-\mathrm{CH}), 20.70\left(\mathrm{CH}_{3}\right)$, $20.58\left(\mathrm{CH}_{3}\right)$; IR $v_{\max }$ (neat): 1522, 1496, 1228, 809, 748; HRMS (ESI-TOF): $m / z$ calcd for $\mathrm{C}_{17} \mathrm{H}_{16} \mathrm{~N}_{2} \mathrm{ONa}$ $(\mathrm{M}+\mathrm{Na})^{+}:$287.1160, found 287.1450.

\subsubsection{Synthesis of Ligands $2 a$ and $2 a^{\prime}$}

$1 H$-pyrazole (a) and 4,5-dibromo-2,7-di-tert-butyl-9,9-dimethyl-9H-xanthene (2) were reacted under similar conditions described above for the synthesis of ligand 1a, except the reaction was kept under magnetic stirring for $48 \mathrm{~h}$ at $160^{\circ} \mathrm{C}$. The crude residue obtained after work up was purified by 
column chromatography using 10\% AcOEt and hexanes as eluent, furnishing the bis-pyrazolyl ligand $\mathbf{2 a}$ in $41 \%$ yield, along with the mono-pyrazolyl byproduct $2 \mathbf{a}^{\prime}$ in approx. $10 \%$ yield.

1,1'-(2,7-di-tert-butyl-9,9-dimethyl-9H-xanthene-4,5-diyl)bis(1H-pyrazole) (2a). Crystalline solid (154 ${ }^{\circ} \mathrm{C}$-decompose); ${ }^{1} \mathrm{H}-\mathrm{NMR}\left(400 \mathrm{MHz}, \mathrm{CDCl}_{3}\right): \delta 7.72(\mathrm{~d}, J=1.8 \mathrm{~Hz}, 2 \mathrm{H}, \mathrm{Xan}), 7.56(\mathrm{~d}, J=2.3 \mathrm{~Hz}$, 2H, Pz), $7.51(\mathrm{~d}, J=2.4 \mathrm{~Hz}, 2 \mathrm{H}, \mathrm{Xan}), 7.46(\mathrm{~d}, J=2.3 \mathrm{~Hz}, 2 \mathrm{H}, \mathrm{Pz}), 6.28(\mathrm{t}, J=2.1 \mathrm{~Hz}, 2 \mathrm{H}, \mathrm{Pz}), 1.74(\mathrm{~s}, 6 \mathrm{H}$, Aliphatic- $\left.\mathrm{CH}_{3}\right), 1.37\left(\mathrm{~s}, 18 \mathrm{H}, t-\mathrm{Bu}_{-} \mathrm{CH}_{3}\right) ;{ }^{13} \mathrm{C}-\mathrm{NMR}\left(100 \mathrm{MHz}, \mathrm{CDCl}_{3}\right): \delta 146.70$ (Xan-C), 140.81 (Xan-C), 140.33 (Pz-CH), 132.10 (Pz-CH), 131.13 (Xan-C), 128.26 (Xan-C), 121.82 (Xan-CH), 121.56 (Xan-CH),

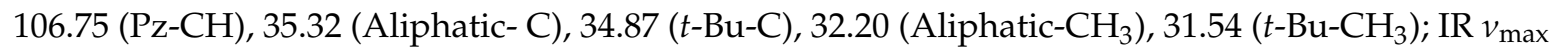
(neat): 2953, 1469, 1453, 1259, 750; HRMS (ESI-TOF): $\mathrm{m} / z$ calcd for $\mathrm{C}_{29} \mathrm{H}_{35} \mathrm{~N}_{4} \mathrm{O}(\mathrm{M}+\mathrm{H})^{+}: 455.2811$, found 455.2831 .

1-(2,7-di-tert-butyl-9,9-dimethyl-9H-xanthen-4-yl)-1H-pyrazole (2a'). White powder (m.p. = 139-140 $\left.{ }^{\circ} \mathrm{C}\right) ;{ }^{1} \mathrm{H}-\mathrm{NMR}\left(400 \mathrm{MHz}, \mathrm{CDCl}_{3}\right): \delta 8.15(\mathrm{~d}, J=2.4 \mathrm{~Hz}, 1 \mathrm{H}, \mathrm{Pz}), 7.76(\mathrm{~d}, J=1.7 \mathrm{~Hz}, 1 \mathrm{H}, \mathrm{Xan}), 7.64(\mathrm{~d}$, $J=2.3 \mathrm{~Hz}, 1 \mathrm{H}, \mathrm{Pz}), 7.43(\mathrm{~d}, J=2.3 \mathrm{~Hz}, 1 \mathrm{H}, \mathrm{Xan}), 7.41(\mathrm{t}, J=2.6 \mathrm{~Hz}, 1 \mathrm{H}), 7.21(\mathrm{dd}, J=8.5,2.3 \mathrm{~Hz}, 1 \mathrm{H}$, Xan), $6.94(\mathrm{~d}, J=8.5 \mathrm{~Hz}, 1 \mathrm{H}, \mathrm{Xan}), 6.50(\mathrm{t}, J=2.1 \mathrm{~Hz}, 1 \mathrm{H}, \mathrm{Pz}), 1.69\left(\mathrm{~s}, 6 \mathrm{H}\right.$, Aliphatic- $\left.\mathrm{CH}_{3}\right), 1.37(\mathrm{~s}$, 9H, $t$-Bu-CH $\left.\mathrm{CH}_{3}\right), 1.33\left(\mathrm{~s}, 9 \mathrm{H}, t-\mathrm{Bu}_{-} \mathrm{CH}_{3}\right) ;{ }^{13} \mathrm{C}-\mathrm{NMR}\left(100 \mathrm{MHz}, \mathrm{CDCl}_{3}\right): \delta 147.89$ (Xan-C), 146.39 (Xan C), 145.88 (Xan-C), 140.66 (Xan-C), 140.21 (Pz-CH), 131.92 (Pz-CH), 131.36 (Xan-C), 129.29 (Xan-C), 127.92, Xan-C) 124.54 (Xan-CH), 122.55 (Xan-CH), 121.51 (Xan-CH), 120.57 (Xan-CH), 115.88 (Xan-CH), 106.44 (Pz-CH), 34.97 ( $t-\mathrm{Bu}-\mathrm{C}$ ), 34.82 ( $t$-Bu-C), 34.66 (Aliphatic-C), 32.25 (Aliphatic- $\left.\mathrm{CH}_{3}\right), 31.68\left(t-\mathrm{Bu}^{-} \mathrm{CH}_{3}\right.$ ), 31.58 ( $\left.t-\mathrm{Bu}-\mathrm{CH}_{3}\right)$; IR $v_{\max }$ (neat): 2960, 1455, 1269, 850, 761; HRMS (ESI-TOF): $\mathrm{m} / z$ calcd for $\mathrm{C}_{26} \mathrm{H}_{33} \mathrm{~N}_{2} \mathrm{O}$ $(\mathrm{M}+\mathrm{H})^{+}: 389.2593$, found 389.2622 .

\subsubsection{Synthesis of Ligands $\mathbf{2} \mathbf{b}$ and $\mathbf{2} \mathbf{b}^{\mathbf{1}}$}

3-mesityl-1H-pyrazole (b) and $\mathbf{2}$ were allowed to react under similar conditions described above for the synthesis of ligand 1a, except the reaction was performed using a lower catalyst loading (10 and $22 \mathrm{~mol} \%$ for $\mathrm{Cu}_{2} \mathrm{O}$ and 1,10-phenanthroline, respectively). The residue obtained after work up was purified by column chromatography using $2.5 \%$ AcOEt in hexanes as eluent, leading to ligand $\mathbf{2 b}$ in $63 \%$ yield, and the byproduct $\mathbf{2} \mathbf{b}^{\mathbf{\prime}}$ in $17 \%$ yield.

1,1'-(2,7-di-tert-butyl-9,9-dimethyl-9H-xanthene-4,5-diyl)bis(3-mesityl-1H-pyrazole) (2b). White crystalline solid (m.p. $\left.=209-210{ }^{\circ} \mathrm{C}\right) ;{ }^{1} \mathrm{H}-\mathrm{NMR}\left(400 \mathrm{MHz}, \mathrm{CDCl}_{3}\right): \delta 7.74(\mathrm{~d}, J=2.3 \mathrm{~Hz}, 2 \mathrm{H}$, Xan), $7.64(\mathrm{~d}, J=2.3 \mathrm{~Hz}, 2 \mathrm{H}, \mathrm{Pz}), 7.46(\mathrm{~d}, J=2.3 \mathrm{~Hz}, 2 \mathrm{H}, \mathrm{Xan}), 6.96(\mathrm{~s}, 4 \mathrm{H}, \mathrm{Mes}), 6.19$ (d, $J=2.3 \mathrm{~Hz}, 2 \mathrm{H}$, $\mathrm{Pz}), 2.33$ (s, 6H, CH $3-\mathrm{Mes}), 2.24\left(\mathrm{~s}, 12 \mathrm{H}, \mathrm{CH}_{3}-\mathrm{Mes}\right), 1.77\left(\mathrm{~s}, 6 \mathrm{H}\right.$, Aliphatic- $\left.\mathrm{CH}_{3}\right), 1.37$ (s, $\left.18 \mathrm{H}, t-\mathrm{Bu}_{-} \mathrm{CH}_{3}\right)$; ${ }^{13} \mathrm{C}-\mathrm{NMR}\left(100 \mathrm{MHz}, \mathrm{CDCl}_{3}\right.$ ): $\delta 151.43$ (Pz-C), 146.59 (Xan-C), 139.84 (Xan-C), 137.49 (Mes-C), 137.43 (Xan-CH), 132.57 (Pz-CH), 130.81 (Xan-CH), 130.64 (Xan-C), 128.14 (Mes-CH), 128.04 (Xan-C), 121.39 (Mes-C), 121.32 (Mes-C), 107.98 (Pz-CH), 35.07 (Aliphatic-C), 34.68 (Aliphatic- $\mathrm{CH}_{3}$ ), 32.35 ( $t$-Bu-C), $31.37\left(t-\mathrm{Bu}^{-} \mathrm{CH}_{3}\right), 21.09$ (Mes- $\left.\mathrm{CH}_{3}\right), 20.65\left(\mathrm{Mes}^{-} \mathrm{CH}_{3}\right)$; IR $v_{\max }$ (neat): 2959, 1458, 1266, 1238, 849, 761, 741; HRMS (ESI-TOF): $m / z$ calcd for $\mathrm{C}_{47} \mathrm{H}_{55} \mathrm{~N}_{4} \mathrm{O}(\mathrm{M}+\mathrm{H})^{+}:$691.4376, found 691.4397 .

1-(5-bromo-2,7-di-tert-butyl-9,9-dimethyl-9H-xanthen-4-yl)-3-mesityl-1H-pyrazole $\left.\quad \mathbf{( 2 b}^{\mathbf{}}\right)$. White crystalline solid (m.p. $\left.=189-191{ }^{\circ} \mathrm{C}\right) ;{ }^{1} \mathrm{H}-\mathrm{NMR}\left(400 \mathrm{MHz}, \mathrm{CDCl}_{3}\right): \delta 8.62(\mathrm{~d}, J=2.4 \mathrm{~Hz}, 1 \mathrm{H}, \mathrm{Pz}), 7.81(\mathrm{~d}$, $J=2.1 \mathrm{~Hz}, 1 \mathrm{H}$, Xan), $7.48(\mathrm{~d}, J=1.9 \mathrm{~Hz}, 1 \mathrm{H}$, Xan), $7.40(\mathrm{~d}, J=2.2 \mathrm{~Hz}, 1 \mathrm{H}$, Xan), $7.38(\mathrm{~d}, J=2.5 \mathrm{~Hz}, 1 \mathrm{H}$, Xan), 6.97 (s, 2H, Mes), 6.41 (d, J = 2.4 Hz, 1H, Pz), 2.34 (s, 3H, Mes-CH $\left.\mathrm{CH}_{3}\right), 2.25$ (s, 6H, Mes-CH $\left.\mathrm{CH}_{3}\right), 1.71$ (s, $6 \mathrm{H}$, Aliphatic- $\left.\mathrm{CH}_{3}\right), 1.37\left(\mathrm{~s}, 9 \mathrm{H}, t-\mathrm{Bu}-\mathrm{CH}_{3}\right), 1.34\left(\mathrm{~s}, 9 \mathrm{H}, t-\mathrm{Bu}_{-} \mathrm{CH}_{3}\right) ;{ }^{13} \mathrm{C}-\mathrm{NMR}\left(100 \mathrm{MHz}, \mathrm{CDCl}_{3}\right): \delta$ 151.26 (Pz-C), 147.29 (Xan-C), 146.43 (Xan-C), 144.98 (Xan-C), 139.75 (Mes-C), 137.68 (Pz-CH), 137.35 (Mes-C), 133.29 (Xan-CH), 131.17 (Xan-C), 130.99 (Xan-C), 130.65 (Xan-C), 128.46 (Xan-CH), 128.16 (Mes-C), 128.07 (Mes-CH), 121.79 (Xan-CH), 120.66 (Xan-CH), 120.45 (Xan-CH), 109.98 (Xan-C), 107.39

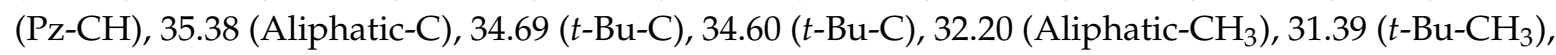
$31.37\left(t-\mathrm{Bu}-\mathrm{CH}_{3}\right), 21.10\left(\mathrm{Mes}-\mathrm{CH}_{3}\right), 20.68\left(\mathrm{Mes}-\mathrm{CH}_{3}\right) ; \mathrm{IR} v_{\max }$ (neat): 2960, 1455, 1269, 850, 761; HRMS (ESI-TOF): $m / z$ calcd for $\mathrm{C}_{35} \mathrm{H}_{42} \mathrm{BrN}_{2} \mathrm{O}(\mathrm{M}+\mathrm{H})^{+}: 585.2480$, found 585.2461. 


\subsubsection{Synthesis of hybrid Ligand $\mathbf{2} \mathbf{b}^{\prime} \mathbf{c}$}

$\mathbf{2} \mathbf{b}^{\mathbf{A}}$ and $1 \mathrm{H}$-imidazole (c) as coupling partners were allowed to react under the reaction conditions described above for the synthesis of ligand $\mathbf{2 b}$. The residue obtained after work up was purified by silica gel column chromatography using $10 \%$ AcOEt in hexanes as eluent, furnishing the hybrid pyrazole-imidazolyl derivative $\mathbf{2} \mathbf{b}^{\prime} \mathbf{c}$ in $78 \%$ yield.

1-(2,7-di-tert-butyl-5-(1H-imidazol-1-yl)-9,9-dimethyl-9H-xanthen-4-yl)-3-mesityl-1H-pyrazole (2b'c). White powder (m.p. $\left.=263-265^{\circ} \mathrm{C}\right) ;{ }^{1} \mathrm{H}-\mathrm{NMR}\left(400 \mathrm{MHz}, \mathrm{CDCl}_{3}\right): \delta 7.67(\mathrm{~d}, J=2.4 \mathrm{~Hz}, 2 \mathrm{H}, \mathrm{Im}), 7.53(\mathrm{~d}$, $J=2.3 \mathrm{~Hz}, 1 \mathrm{H}, \mathrm{Pz}), 7.44(\mathrm{~d}, J=2.4 \mathrm{~Hz}, 1 \mathrm{H}, \mathrm{Xan}), 7.39(\mathrm{~d}, J=2.4 \mathrm{~Hz}, 1 \mathrm{H}, \mathrm{Xan}), 7.20(\mathrm{~d}, J=2.3 \mathrm{~Hz}, 1 \mathrm{H}$, Xan), 7.11-7.08 (m, 1H, Xan), $7.04(\mathrm{t}, J=1.3 \mathrm{~Hz}, 1 \mathrm{H}, \mathrm{Im}), 6.95-6.93(\mathrm{~m}, 2 \mathrm{H}, \mathrm{Mes}), 6.19(\mathrm{~d}, J=2.4 \mathrm{~Hz}, 1 \mathrm{H}$, $\mathrm{Pz}), 2.32\left(\mathrm{~s}, 3 \mathrm{H}, \mathrm{Mes}-\mathrm{CH}_{3}\right), 2.20\left(\mathrm{~s}, 6 \mathrm{H}, \mathrm{Mes}-\mathrm{CH}_{3}\right), 1.75\left(\mathrm{~s}, 6 \mathrm{H}\right.$, Aliphatic- $\left.\mathrm{CH}_{3}\right), 1.37\left(\mathrm{~s}, 9 \mathrm{H}, t-\mathrm{Bu}_{-} \mathrm{CH}_{3}\right)$, $1.34\left(\mathrm{~s}, 9 \mathrm{H}, t-\mathrm{Bu}-\mathrm{CH}_{3}\right) ;{ }^{13} \mathrm{C}-\mathrm{NMR}\left(100 \mathrm{MHz}, \mathrm{CDCl}_{3}\right): \delta 151.41$ (Pz-C), 146.83 (Xan-C), 146.72 (Xan-C), 142.11 (Xan-C), 139.56 (Mes-C), 137.56 (Xan-C), 137.33 (Pz-CH), 131.82 (Mes-C), 131.56 (Im-CH), 130.92 (Xan-CH), 130.65 (Xan-C), 129.48 (Im-CH), 128.31 (Mes-C), 128.09 (Mes-CH), 124.94 (Xan-C), 122.67 (Xan-C), 121.94 (Im-CH), 120.87 (Xan-CH), 120.75 (Xan-CH), 108.26 (Pz-CH), 35.23 (Aliphatic-C), 34.72 ( $t$-Bu-C), $34.70(t-\mathrm{Bu}-\mathrm{C}), 32.05$ (Aliphatic- $\left.\mathrm{CH}_{3}\right), 31.40\left(t-\mathrm{Bu}^{\left.-\mathrm{CH}_{3}\right)}, 31.39\left(t-\mathrm{Bu}^{-} \mathrm{CH}_{3}\right), 21.11\left(\mathrm{Mes}-\mathrm{CH}_{3}\right)\right.$, 20.65 (Mes- $\mathrm{CH}_{3}$ ); IR $v_{\max }$ (neat): 2953, 1497, 1456, 1271, 760; HRMS (ESI-TOF): $\mathrm{m} / z$ calcd for $\mathrm{C}_{38} \mathrm{H}_{45} \mathrm{~N}_{4} \mathrm{O}$ $(\mathrm{M}+\mathrm{H})^{+}: 573.3588$, found 573.3580 .

\subsubsection{Synthesis of Hybrid Ligand $\mathbf{2} \mathbf{a}^{\prime} \mathbf{d}$}

Ligand $\mathbf{2} \mathbf{a}^{\prime} \mathbf{d}$ was synthesized following a recently reported $\mathrm{C}-\mathrm{H}$ activation protocol [40]. An overn dried Schelnk flask, evacuated and backfilled with argon (3x), was charged with $\mathrm{PdCl}_{2}(5 \mathrm{~mol} \%)$, $\mathrm{CuCl}_{2}(5 \mathrm{~mol} \%), \mathbf{2} \mathbf{a}^{\prime}(0.2 \mathrm{mmol})$, and diphenyl diselenide (d, $\left.0.4 \mathrm{mmol}\right)$. Two $\mathrm{mL}$ of degassed DMSO were added to the reaction flask and the resulting mixture was kept overnight under magnetic stirring at $120^{\circ} \mathrm{C}$. After cooling to room temperature, the reaction mixture was taken up in $5 \mathrm{~mL}$ of ethyl acetate and filtered through a small plug of celite. The filtrate was dried over $\mathrm{MgSO}_{4}$ and solvent removal under reduced pressure provided a crude solid product. This residue was purified by column chromatography using $10 \%$ ethyl acetate in hexanes as eluent, leading to the titled compound $\mathbf{2} \mathbf{a}^{\mathbf{\prime}} \mathbf{d}$ in $58 \%$ yield.

1-(2,7-di-tert-butyl-9,9-dimethyl-5-(phenylselanyl)-9H-xanthen-4-yl)-1H-pyrazole (2a'd). White powder (m.p. $\left.=144-146{ }^{\circ} \mathrm{C}\right) ;{ }^{1} \mathrm{H}-\mathrm{NMR}\left(400 \mathrm{MHz}, \mathrm{CDCl}_{3}\right): \delta 8.32(\mathrm{~d}, J=0.6 \mathrm{~Hz}, 1 \mathrm{H}, \mathrm{Pz}), 7.83(\mathrm{~d}, J=0.5 \mathrm{~Hz}$, $1 \mathrm{H}, \mathrm{Xan}), 7.66(\mathrm{~d}, J=2.3 \mathrm{~Hz}, 1 \mathrm{H}, \mathrm{Xan}), 7.44(\mathrm{~d}, J=2.3 \mathrm{~Hz}, 1 \mathrm{H}, \mathrm{Xan}), 7.42(\mathrm{~d}, J=2.3 \mathrm{~Hz}, 1 \mathrm{H}, \mathrm{Xan})$, 7.38-7.40 (m, 2H, Se-Ar), 7.27 (d, J = 1.3 Hz, 1H, Pz), 7.25 (d, J = 7.4 Hz, 1H, Se-Ar), 7.24-7.17 (m, 2H, Se-Ar), $6.86(\mathrm{~d}, J=8.5 \mathrm{~Hz}, 1 \mathrm{H}, \mathrm{Pz}), 1.68(\mathrm{~s}, 6 \mathrm{H}), 1.38(\mathrm{~s}, 9 \mathrm{H}), 1.33(\mathrm{~s}, 9 \mathrm{H}):{ }^{13} \mathrm{C}-\mathrm{NMR}\left(100 \mathrm{MHz}, \mathrm{CDCl}_{3}\right)$ :

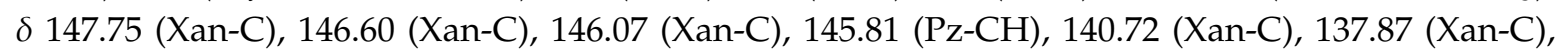
133.49 (Se-Ar-C), 131.57 (Xan-C), 129.41 (Se-Ar-CH), 129.31 (Se-Ar-CH), 129.22 (Se-Ar-CH), 127.43 (Xan-C), 126.31 (Xan_CH), 124.62 (Pz-CH), 122.56 (Xan-CH), 122.06 (Xan-C), 120.29 (Xan-CH), 115.89 (Xan-CH), 101.95 (Pz-CH), 35.01 ( $t-B u-C), 34.88$ ( $t$-Bu-C), 34.69 (Aliphatic-C), 32.25 (Aliphatic- $\mathrm{CH}_{3}$ ), $31.68\left(t-\mathrm{Bu}-\mathrm{CH}_{3}\right), 31.59\left(t-\mathrm{Bu}-\mathrm{CH}_{3}\right) ; \mathrm{IR} v_{\max }$ (neat): 2958, 2867, 1497, 1511, 1393, 940, 766; HRMS (ESI-TOF): $\mathrm{m} / \mathrm{z}$ calcd for $\mathrm{C}_{32} \mathrm{H}_{36} \mathrm{~N}_{2} \mathrm{OSeNa}(\mathrm{M}+\mathrm{Na})^{+}: 567.1918$, found 567.0428.

\subsection{X-ray Crystallography of $\mathbf{1}, \mathbf{1} \mathbf{a}, \mathbf{2} \mathbf{a}, \mathbf{2} \mathbf{b}$ and $\mathbf{2} \mathbf{b}^{\mathbf{\prime}}$}

A Bruker D8 Venture Photon 100 dual source diffractometer was used to collect X-ray data for the structural analysis of the compounds. Data were collected using $\mathrm{Cu}-K \alpha(\lambda=1.54178 \AA)$ or Mo-K $\alpha(\lambda=0.71073 \AA)$ radiations, and a combination of $\phi$ and $\omega$ scans was carried out to obtain at least one unique data set. The crystal structures were solved using direct methods in the SHELXS program [45]. The final structures were refined using SHELXL, where the remaining atoms were located from difference Fourier synthesis in which anisotropic displacement parameters were applied to all non-hydrogen atoms, followed by full-matrix least-squares refinement based on $F^{2}$. All hydrogen atoms were placed in ideal positions and refined as riding atoms with relative isotropic displacement 
parameters. Additional structural information for the compounds are provided in Supporting Information (Table S5). Crystallographic data for the structures were deposited in the Cambridge Crystallographic Data Centre as supplementary publication number CCDC 1893376 (1), 1893381 (1a), $1938492(\mathbf{2 a}), 1893386(\mathbf{2 b})$, and $1893396\left(\mathbf{2} \mathbf{b}^{\mathbf{}}\right)$. Copies of the data related to the crystals can be obtained via www.ccdc.cam.ac.uk/data_request/cif.

\subsection{General Procedure for SM Cross-Coupling Reaction}

For a typical SM cross-coupling reaction, an oven dried resealable Schlenk flask, evacuated and refilled with argon $(3 \mathrm{x})$, was charged with $\mathrm{Pd}(\mathrm{OAc})_{2}(1.0 \mathrm{~mol} \%), \mathbf{2 a}(1.1 \mathrm{~mol} \%)$, and $2 \mathrm{~mL}$ of degassed DMF. The resulting reaction mixture was stirred at room temperature for $15 \mathrm{~min}$, turning into a yellow solution. Then, aryl halide $(0.5 \mathrm{mmol})$, aryl boronic acid $(0.75 \mathrm{mmol}), \mathrm{K}_{2} \mathrm{CO}_{3}(1.0 \mathrm{mmol})$, and additional DMF $(2 \mathrm{~mL})$ were added and the Schlenk tube, which was sealed under argon atmosphere. The resulting reaction mixture was kept under magnetic stirring at $80^{\circ} \mathrm{C}$ for the specified time. The reaction mixture was then cooled to room temperature and taken up in $5 \mathrm{~mL}$ of ethyl acetate, followed by filtration through a short plug of celite (washed with additional $5 \mathrm{~mL}$ of ethyl acetate). The filtrate was dried over anhydrous $\mathrm{MgSO}_{4}$ and concentrated under reduced pressure. The residue was purified using flash silica gel column chromatography ( $2-5 \%$ ethyl acetate in hexanes as eluent), leading to the corresponding isolated cross-coupling product.

\section{Conclusions}

In conclusion, this work highlights the synthesis of new mono- and bis-pyrazole compounds bearing a flexible $p$-tolyl ether or a rigid xanthene backbone as pyrazolyl analogues of DPEphos and Xantphos ligands, respectively, as well as their potential as ligands leading to active catalyst systems for the Pd-catalysed Suzuki-Miyaura reaction. The synthesis of the bis-pyrazolyl analogues $\mathbf{1 a}, \mathbf{2} \mathbf{a}, \mathbf{2} \mathbf{b}$, and the hybrid pyrazolyl-imidazolyl analogue $\mathbf{2} \mathbf{b}^{\prime} \mathbf{c}$ was achieved by following the Ullmann coupling protocol, while the hybrid pyrazolyl-selanyl anaolgue $2 \mathbf{a}^{\prime} \mathbf{d}$ was synthesized using a first Ullman coupling step followed by a $\mathrm{C}-\mathrm{H}$ activation reaction. The $\mathrm{Pd}(\mathrm{OAc})_{2} / 2 \mathbf{a}$ based catalytic system developed in this work efficiently catalysed the SM cross-coupling reaction of aryl iodides and aryl bromides bearing electron rich and poor substituents, providing the corresponding cross-coupling products in good to excellent yields. In addition, moderate yields were obtained for the cross-coupling reactions employing aryl chlorides containing electron-withdrawing groups at $p$-position, whereas only poor yields were obtained for the electron-poor derivatives. Further studies to explore the applications of the newly synthesized ligands in other organic transformations, their coordination chemistry, as well their photophysical properties will be carried out as a sequence of this work.

Supplementary Materials: The following are available online at http://www.mdpi.com/2073-4344/9/9/718/s1, the ${ }^{1} \mathrm{H}$ - and ${ }^{13} \mathrm{C}-\mathrm{NMR}$ spectra of synthetic precursors and pyrazolyl ligands, the crystallographic data and structure refinement parameters for $\mathbf{1}, \mathbf{1} \mathbf{a}, \mathbf{2} \mathbf{a}, \mathbf{2} \mathbf{b}$ and $\mathbf{2} \mathbf{b}^{\prime}$, the analytical and spectroscopic data of SM cross-coupling products, the ${ }^{1} \mathrm{H}$ - and ${ }^{13} \mathrm{C}-\mathrm{NMR}$ spectra of SM cross-coupling products.

Author Contributions: Conceptualization, A.M.; methodology, Z.H., C.S., and R.R.; formal analysis, R.S., Z.H., and C.S.; funding acquisition, A.M.; investigation, Z.H., C.S., R.R., and R.D.; writing—original draft preparation, Z.H., A.M., and C.S.; writing-review and editing, Z.H., A.M., and C.S.; supervision, A.M.; validation, Z.H. and C.S.

Funding: We thank TWAS-CNPq for providing the post-graduate fellowship to Zahid Hussain (190090/2014-9), CNPq for providing Cristiane S. Schwalm (157879/2015-1) and Raoní S. Rambo (150671/2015-6) post-doctoral fellowships, BIC-FAPERGS for providing the undergraduate fellowship to Renieidy F. C. Dias and UFGD for the Junior Researcher Fellowship to Cristiane S. Schwalm. We also thank the following Brazilian agencies for the partial financial support: CNPq (307514/2013-7), CNPq (304132/2017-9), PRONEX-FAPERGS 16/2551-0000, CAPES (001), and INCT-Catálise (465454/ 2014-3).

Acknowledgments: X-ray crystallography analyses were performed at the Department of Chemistry, X-ray Diffraction Facility of UFPR. We acknowledge Prof. Jaisa F. Soares (UFPR) for providing the X-ray facility and Francielle S. Santana for performing the single crystal X-ray crystallographic analysis of the compounds. We also thank Prof. L. Streit (UFRGS) for proofreading the revised manuscript. 
Conflicts of Interest: The authors declare no conflict of interest.

\section{References}

1. Fairlamb, I. Metal-Catalyzed Cross-Coupling Reactions and More. 3 Volume Set. Edited by Armin de Meijere, Stefan Brse and Martin Oestreich. Angew. Chem. Int. Ed. 2014, 53. [CrossRef]

2. Shinde, V.V.; Jeong, D.; Jung, S. An Amino-Chain Modified $\beta$-cyclodextrin: A Supramolecular Ligand for $\mathrm{Pd}(\mathrm{OAc})_{2}$ Acceleration in Suzuki-Miyaura Coupling Reactions in Water. Catalysts 2019, 9, 111. [CrossRef]

3. Zuidema, E.; Goudriaan, P.E.; Swennenhuis, B.H.G.; Kamer, P.C.J.; van Leeuwen, P.W.N.M.; Lutz, M.; Spek, A.L. Phenoxaphosphine-Based Diphosphine Ligands. Synthesis and Application in the Hydroformylation Reaction. Organometallics 2010, 29, 1210-1221. [CrossRef]

4. Li, C.; Xiao, G.; Zhao, Q.; Liu, H.; Wang, T.; Tang, W. Sterically demanding aryl-alkyl Suzuki-Miyaura coupling. Org. Chem. Front. 2014, 1, 225-229. [CrossRef]

5. Kamer, P.C.J.; van Leeuwen, P.W.N.M.; Reek, J.N.H. Wide Bite Angle Diphosphines: Xantphos Ligands in Transition Metal Complexes and Catalysis. Acc. Chem. Res. 2001, 34, 895-904. [CrossRef] [PubMed]

6. Adams, G.M.; Weller, A.S. POP-type ligands: Variable coordination and hemilabile behaviour. Coord. Chem. Rev. 2018, 355, 150-172. [CrossRef]

7. Birkholz, M.N.; Freixa, Z.; van Leeuwen, P.W.N.M. Bite angle effects of diphosphines in C-C and C-X bond forming cross coupling reactions. Chem. Soc. Rev. 2009, 38, 1099-1118. [CrossRef]

8. Andreychuk, N.R.; Emslie, D.J.H. Potassium-Alkane Interactions within a Rigid Hydrophobic Pocket. Angew. Chem. Int. Ed. 2013, 52, 1696-1699. [CrossRef]

9. Takano, S.; Takeuchi, D.; Osakada, K. Olefin Polymerization Catalyzed by Double-Decker Dipalladium Complexes: Low Branched Poly( $\alpha$-Olefin)s by Selective Insertion of the Monomer Molecule. Chem. A Eur. J. 2015, 21, 16209-16218. [CrossRef]

10. Komuro, T.; Kitano, T.; Yamahira, N.; Ohta, K.; Okawara, S.; Mager, N.; Okazaki, M.; Tobita, H. Directed ortho-C-H Silylation Coupled with trans-Selective Hydrogenation of Arylalkynes Catalyzed by Ruthenium Complexes of a Xanthene-Based Si,O,Si-Chelate Ligand, "Xantsil". Organometallics 2016, 35, 1209-1217. [CrossRef]

11. Diéguez, M.; Claver, C.; Masdeu-Bultó, A.M.; Ruiz, A.; van Leeuwen, P.W.N.M.; Schoemaker, G.C. High-Pressure Infrared Studies of Rhodium Complexes Containing Thiolate Bridge Ligands under Hydroformylation Conditions. Organometallics 1999, 18, 2107-2115. [CrossRef]

12. van Leeuwen, P.W.N.M.; Kamer, P.C.J. Featuring Xantphos. Catal. Sci. Technol. 2018, 8, 26-113. [CrossRef]

13. Yoo, K.S.; Yoon, C.H.; Jung, K.W. Oxidative Palladium(II) Catalysis: A Highly Efficient and Chemoselective Cross-Coupling Method for Carbon-Carbon Bond Formation under Base-Free and Nitrogenous-Ligand Conditions. J. Am. Chem. Soc. 2006, 128, 16384-16393. [CrossRef]

14. Punji, B.; Ganesamoorthy, C.; Balakrishna, M.S. Suzuki cross-coupling reactions catalyzed by palladium complex of an inexpensive phosphinite, 2-diphenylphosphinoxynaphthyl. J. Mol. Catal. A Chem. 2006, 259, 78-83. [CrossRef]

15. Miyaura, N.; Suzuki, A. Palladium-Catalyzed Cross-Coupling Reactions of Organoboron Compounds. Chem. Rev. 1995, 95, 2457-2483. [CrossRef]

16. Suzuki, A. Recent advances in the cross-coupling reactions of organoboron derivatives with organic electrophiles, 1995-1998. J. Organomet. Chem. 1999, 576, 147-168. [CrossRef]

17. Kotha, S.; Lahiri, K.; Kashinath, D. Recent applications of the Suzuki-Miyaura cross-coupling reaction in organic synthesis. Tetrahedron 2002, 58, 9633-9695. [CrossRef]

18. Seechurn, C.C.C.; Kitching, M.O.; Colacot, T.J.; Snieckus, V. Palladium-Catalyzed Cross-Coupling: A Historical Contextual Perspective to the 2010 Nobel Prize. Angew. Chem. Int. Ed. 2012, 51, 5062-5085. [CrossRef]

19. Biajoli, A.F.P.; Schwalm, C.S.; Limberger, J.; Claudino, T.S.; Monteiro, A.L. Recent Progress in the Use of Pd-Catalyzed C-C Cross-Coupling Reactions in the Synthesis of Pharmaceutical Compounds. J. Braz. Chem. Soc. 2014, 25, 2186-2214. [CrossRef]

20. Kumbhar, A. Functionalized nitrogen ligands for palladium catalyzed cross-coupling reactions (part I). J. Organomet. Chem. 2017, 848, 22-88. [CrossRef] 
21. Kumbhar, A. Functionalized nitrogen ligands $(\mathrm{CN})$ for palladium catalyzed cross-coupling reactions (part II). J. Organomet. Chem. 2019, 881, 79-129. [CrossRef]

22. Li, J.H.; Liu, W.J. Dabco as an Inexpensive and Highly Efficient Ligand for Palladium-Catalyzed Suzuki-Miyaura Cross-Coupling Reaction. Org. Lett. 2004, 6, 2809-2811. [CrossRef]

23. Li, J.H.; Zhu, Q.M.; Xie, Y.X. Pd(OAc) $)_{2} / \mathrm{DABCO}$-catalyzed Suzuki-Miyaura cross-coupling reaction in DMF. Tetrahedron 2006, 62, 10888-10895. [CrossRef]

24. Doucet, H. Suzuki-Miyaura Cross-Coupling Reactions of Alkylboronic Acid Derivatives or Alkyltrifluoroborates with Aryl, Alkenyl or Alkyl Halides and Triflates. Eur. J. Org. Chem. 2008, 2008, 2013-2030. [CrossRef]

25. Weng, Z.; Teo, S.; Hor, T.S.A. Metal Unsaturation and Ligand Hemilability in Suzuki Coupling. Acc. Chem. Res. 2007, 40, 676-684. [CrossRef]

26. Zhang, C.; Huang, J.; Trudell, M.L.; Nolan, S.P. Palladium-Imidazol-2-ylidene Complexes as Catalysts for Facile and Efficient Suzuki Cross-Coupling Reactions of Aryl Chlorides with Arylboronic Acids. J. Org. Chem. 1999, 64, 3804-3805. [CrossRef]

27. Ibrahim, M.B.; Shakil Hussain, S.M.; Fazal, A.; Fettouhi, M.; El Ali, B. Effective palladium(II)-bis(oxazoline) catalysts: Synthesis, crystal structure, and catalytic coupling reactions. J. Coord. Chem. 2015, 68, 432-448. [CrossRef]

28. van Koten, G. The Monoanionic ECE-Pincer Ligand: A Versatile Privileged Ligand Platform-General Considerations. In Organometallic Pincer Chemistry; van Koten, G., Milstein, D., Eds.; Springer: Berlin/Heidelberg, Germany, 2013.

29. Peral, D.; Gómez-Villarraga, F.; Sala, X.; Pons, J.; Carles Bayón, J.; Ros, J.; Guerrero, M.; Vendier, L.; Lecante, P.; García-Antón, J.; et al. Palladium catalytic systems with hybrid pyrazole ligands in C-C coupling reactions. Nanoparticles versus molecular complexes. Catal. Sci. Technol. 2013, 3, 475-489. [CrossRef]

30. Ojwach, S.O.; Darkwa, J. Pyrazole and (pyrazol-1-yl)metal complexes as carbon-carbon coupling catalysts. Inorg. Chim. Acta 2010, 363, 1947-1964. [CrossRef]

31. Li, F.; Hor, T.S.A. Benzimidazolium-Pyrazole-Palladium(II) Complexes: New and Efficient Catalysts for Suzuki, Heck and Sonogashira Reactions. Adv. Synth. Catal. 2008, 350, 2391-2400. [CrossRef]

32. Montoya, V.; Pons, J.; Branchadell, V.; Garcia-Antón, J.; Solans, X.; Font-Bardía, M.; Ros, J. Highly Efficient Pyridylpyrazole Ligands for the Heck Reaction. A Combined Experimental and Computational Study. Organometallics 2008, 27, 1084-1091. [CrossRef]

33. Ocansey, E.; Darkwa, J.; Makhubela, B.C.E. Synthesis, characterization and evaluation of bulky bis(pyrazolyl)palladium complexes in Suzuki-Miyaura cross-coupling reactions. RSC Adv. 2018, 8, 13826-13834. [CrossRef]

34. Li, K.; Darkwa, J.; Guzei, I.A.; Mapolie, S.F. Synthesis and evaluation of substituted pyrazoles palladium(II) complexes as ethylene polymerization catalysts. J. Organomet. Chem. 2002, 660, 108-115. [CrossRef]

35. Obuah, C.; Omondi, B.; Nozaki, K.; Darkwa, J. Solvent and co-catalyst dependent pyrazolylpyridinamine and pyrazolylpyrroleamine nickel(II) catalyzed oligomerization and polymerization of ethylene. J. Mol. Catal. A Chem. 2014, 382, 31-40. [CrossRef]

36. Matos, K.; de Oliveira, L.L.; Favero, C.; Monteiro, A.L.; Hörner, M.; Carpentier, J.-F.; Gil, M.P.; Casagrande, O.L. Palladium complexes based on tridentate pyrazolyl-ligands: Synthesis, structures and use in Suzuki cross-coupling reactions. Inorg. Chim. Acta 2009, 362, 4396-4402. [CrossRef]

37. Das, B.; Venkateswarlu, K.; Majhi, A.; Siddaiah, V.; Reddy, K.R. A facile nuclear bromination of phenols and anilines using NBS in the presence of ammonium acetate as a catalyst. J. Mol. Catal. A Chem. 2007, 267, 30-33. [CrossRef]

38. Kreisel, G.; Rudolph, G.; Schulze, D.K.W.; Poppitz, W. Bromierte Diphenylether-Eine entscheidende Zwischenstufe auf dem Weg zu synthetischen Schmierstoffen. Mon. Für Chem. Chem. Mon. 1992, 123, 1153-1161. [CrossRef]

39. Mudge, M.; Patel, A.R.; Bingül, M.; Bhadbhade, M.; Colbran, S.B. An aryl-bridged dixanthene scaffold for building multinucleating ligands and supramolecular assemblies: Syntheses and structures. Tetrahedron 2017, 73, 6401-6409. [CrossRef]

40. Nishino, K.; Tsukahara, S.; Ogiwara, Y.; Sakai, N. Palladium(II)/Copper(II)-Catalyzed C-H Sulfidation or Selenation of Arenes Leading to Unsymmetrical Sulfides and Selenides. Eur. J. Org. Chem. 2019, 2019, 1588-1593. [CrossRef] 
41. Beletskaya, I.P.; Ananikov, V.P. Unusual Influence of the Structures of Transition Metal Complexes on Catalytic C-S and C-Se Bond Formation Under Homogeneous and Heterogeneous Conditions. Eur. J. Org. Chem. 2007, 2007, 3431-3444. [CrossRef]

42. Zim, D.; Nobre, S.M.; Monteiro, A.L. Suzuki cross-coupling reaction catalyzed by sulfur-containing palladacycles: Formation of palladium active species. J. Mol. Catal. A Chem. 2008, 287, 16-22. [CrossRef]

43. Liu, J.; Cao, R.; Wu, Q.; Ma, C.; Wang, Z.; Peng, W.; Song, H. Synthesis and antibacterial evaluation of novel 4-alkyl substituted phenyl $\beta$-aldehyde ketone derivatives. Eur. J. Med. Chem. 2009, 44, 1737-1744. [CrossRef]

44. Rheingold, A.L.; White, C.B.; Trofimenko, S. Hydrotris(3-mesitylpyrazol-1-yl)borate and hydrobis(3-mesitylpyrazol-1-yl)(5-mesitylpyrazol-1-yl)borate: Symmetric and asymmetric ligands with rotationally restricted aryl substituents. Inorg. Chem. 1993, 32, 3471-3477. [CrossRef]

45. Sheldrick, G. A short history of SHELX. Acta Crystallogr. Sect. A 2008, 64, 112-122. [CrossRef]

(C) 2019 by the authors. Licensee MDPI, Basel, Switzerland. This article is an open access article distributed under the terms and conditions of the Creative Commons Attribution (CC BY) license (http://creativecommons.org/licenses/by/4.0/). 